\title{
Copper Coordination Features of Human Islet Amyloid Polypeptide: The Type 2 Diabetes Peptide
}

\author{
Carolina Sánchez-López, ${ }^{\dagger}$ Rodrigo Cortés-Mejía, ${ }^{\ddagger}$ Marco C. Miotto, ${ }^{\S}$ Andres Binolfi, ${ }^{\S}$ \\ Claudio O. Fernández, Jorge M. del Campo, ${ }^{\ddagger}$ and Liliana Quintanar*,† \\ ${ }^{\dagger}$ Departamento de Química, Centro de Investigación y de Estudios Avanzados (Cinvestav), Mexico City, Mexico \\ ${ }^{\ddagger}$ Departamento de Física y Química Teórica, Facultad de Química, Universidad Nacional Autónoma de México (UNAM), Mexico \\ City, Mexico \\ ${ }^{\S}$ Max Planck Laboratory for Structural Biology, Chemistry and Molecular Biophysics of Rosario (MPLbioR, UNR-MPIbpC) and \\ Instituto de Investigaciones para el Descubrimiento de Fármacos de Rosario (IIDEFAR, UNR-CONICET), Universidad Nacional de \\ Rosario, Ocampo y Esmeralda, S2002LRK Rosario, Argentina
}

\section{Supporting Information}

ABSTRACT: Human islet amyloid polypeptide (hIAPP) is the major component of amyloid deposits found in pancreatic $\beta$-cells of patients with type 2 diabetes (T2D). Copper ions have an inhibitory effect on the amyloid aggregation of hIAPP, and they may play a role in the etiology of T2D. However, deeper knowledge of the structural details of the copperhIAPP interaction is required to understand the molecular mechanisms involved. Here, we performed a spectroscopic study of $\mathrm{Cu}$ (II) binding to hIAPP and several variants, using electron paramagnetic resonance (EPR), nuclear magnetic resonance (NMR), electronic absorption, and circular dichroism (CD) in the UV-vis region in combination with Born-Oppenheimer molecular dynamics (BOMD) and density functional theory geometry optimizations. We find that $\mathrm{Cu}$ (II) binds to the imidazole N1 of His 18 , the deprotonated amides of Ser19 and Ser20, and an oxygen-based ligand provided by Ser20, either via its hydroxyl group or its backbone carbonyl, while Asn 22 might also play a role as an axial ligand. Ser20 plays a crucial role in stabilizing $\mathrm{Cu}$ (II) coordination toward the Cterminal, providing a potential link between the S20G mutation associated with early onset of T2D, its impact in Cu binding properties, and hIAPP amyloid aggregation. Our study defines the nature of the coordination environment in the Cu(II)-hIAPP complex, revealing that the amino acid residues involved in metal ion binding are also key residues for the formation of $\beta$-sheet structures and amyloid fibrils. $\mathrm{Cu}$ (II) binding to hIAPP may lead to the coexistence of more than one coordination mode, which in turn could favor different sets of $\mathrm{Cu}$-induced conformational ensembles. $\mathrm{Cu}$-induced hIAPP conformers would display a higher energetic barrier to form amyloid fibrils, hence explaining the inhibitory effect of Cu ions in hIAPP aggregation. Overall, this study provides further structural insights into the bioinorganic chemistry of T2D.

\section{INTRODUCTION}

Human islet amyloid polypeptide (hIAPP) or amylin is an amyloidogenic C-terminally amidated peptide of 37 residues with sequence KCNTATCATQRLANFLVHSSNNFGAILSSTNVGSNTY-NH$H_{2}$. It has a disulfide bridge between residues 2 and 7, and it is cosecreted with insulin by $\beta$-cells in the islets of Langerhans in the pancreas. ${ }^{1}$ This peptide is the major component of amyloid deposits found in pancreatic islets affecting up to $80 \%$ of islets ${ }^{2}$ in more than $90 \%$ of patients with type 2 diabetes. ${ }^{3}$

Type 2 diabetes is a multifactorial disease with genetic and environmental components, characterized by a decreased ability of insulin to stimulate glucose metabolism ${ }^{4}$ and a $\beta$-cell secretory dysfunction and/or decreased $\beta$-cell mass. ${ }^{5}$ Some mammalian species including humans, monkeys, felines (domestic cat, lynx, cougars), and raccoons, are prone to form amyloid deposits in pancreatic islets, rendering them susceptible to type 2 diabetes. Remarkably, islet amyloid is not found in islets of rodents. ${ }^{6}$ Amyloid deposits are mostly present in extracellular sites in diabetic animals and may be extended to adjacent capillaries affecting islet function, which can be associated with the destruction and displacement of cells. ${ }^{2}$ Moreover, it has been observed that patients with insulin resistance have higher plasma concentrations of hIAPP than healthy people. ${ }^{6}$ hIAPP is toxic to $\beta$-cells in vitro in its fibrillar form. ${ }^{7}$ Several studies suggest that the species with highest cytotoxicity are the protofibrils and oligomers, and not the

Received: August 12, 2016 
Table 1. Peptide Sequences and EPR Parameters ${ }^{a}$ for Their Complexes with Cu(II)

\begin{tabular}{|c|c|c|c|c|}
\hline peptide & sequence & $g_{\|}$ & $A_{\|}\left(\times 10^{-4} \mathrm{~cm}^{-1}\right)$ & coordination mode \\
\hline hIAPP(15-22) & Ac-FLVHSSNN-NH ${ }_{2}$ & 2.234 & 164 & $3 \mathrm{~N} 1 \mathrm{O}$ \\
\hline hIAPP(18-22) & Ac-HSSNN-NH ${ }_{2}$ & 2.239 & 158 & $3 \mathrm{~N} 1 \mathrm{O}$ \\
\hline hIAPP(15-22)S19P & Ac-FLVHPSNN-NH ${ }_{2}$ & 2.233 & 173 & $2 \mathrm{~N} 2 \mathrm{O}$ \\
\hline $\operatorname{hIAPP}(18-22)$ S19Sar ${ }^{b}$ & Ac-HSarSNN-NH ${ }_{2}$ & 2.296 & 150 & $2 \mathrm{~N} 2 \mathrm{O} / 1 \mathrm{~N} 3 \mathrm{O}$ \\
\hline $\operatorname{hIAPP}(18-22) \mathrm{S}^{20 S a r}{ }^{b}$ & Ac-HSSarNN-NH ${ }_{2}$ & 2.281 & 168 & $2 \mathrm{~N} 2 \mathrm{O} / 1 \mathrm{~N} 3 \mathrm{O}$ \\
\hline hIAPP(18-22) S19A & Ac-HASNN-NH ${ }_{2}$ & 2.240 & 159 & $3 \mathrm{~N} 1 \mathrm{O}$ \\
\hline hIAPP(18-22) S20A & Ac-HSANN-NH ${ }_{2}$ & 2.246 & 151 & $3 \mathrm{~N} 1 \mathrm{O}$ \\
\hline hIAPP(18-22) N21Q & Ac-HSSQN-NH ${ }_{2}$ & 2.239 & 156 & $3 \mathrm{~N} 1 \mathrm{O}$ \\
\hline hIAPP(18-22) N22Q & Ac-HSSNQ-NH ${ }_{2}$ & 2.240 & 151 & $3 \mathrm{~N} 1 \mathrm{O}$ \\
\hline hIAPP(18-22) N22L & Ac-HSSNL-NH ${ }_{2}$ & 2.244 & 146 & $3 \mathrm{~N} 1 \mathrm{O}$ \\
\hline
\end{tabular}

${ }^{a} g_{\|}$and $A_{\|}$values values were obtained from the simulation of each spectrum; a full list of EPR parameters is given in Table S1. ${ }^{b}$ Sar $=$ sarcosine or $N$-methylglycine.

mature fibrils formed by hIAPP. ${ }^{1}$ Amyloid aggregates of hIAPP can induce apoptosis of $\beta$-cells through various mechanisms, which include disruption of lipid membranes, permeabilization of cell membranes, oxidative stress, activation of calpain-2, and mitochondrial dysfunction, among others. ${ }^{8}$

The process of amyloid formation has been studied extensively, leading to the identification of many factors that may affect its aggregation pathway, including genetic factors such as the S20G mutation in hIAPP, ${ }^{9}$ seeding process of the fragments of the hIAPP precursor (proIAPP) and hIAPP glycation. ${ }^{2}$ The ability of hIAPP to form amyloid fibrils resides largely in its primary sequence. The region comprising residues 20-29 (SNNFGAILSS) is key to amyloid formation, ${ }^{1,8}$ but the regions $8-20$ and $30-37$ also form fibers. ${ }^{2}$ The inability of rodent IAPP to form fibrils is attributed to sequence differences in the 20-29 region (SNNLGPVLPP for rodent IAPP), where the presence of three proline residues is thought to block the $\beta$ sheet formation. ${ }^{10}$

The formation of hIAPP amyloid fibrils can also be impacted by other molecules, such as proteins, peptide hormones (like insulin), and metal ions. ${ }^{11}$ The role of metal ions in diseases associated with protein aggregation processes has been studied extensively, particularly for the case of amyloidogenic proteins, such as amyloid- $\beta, \alpha$-synuclein, and prion protein. An important role for metal ions, mainly copper and zinc, has been identified in the amyloid aggregation of these proteins. $^{12-14}$ In the case of hIAPP, various studies have suggested that zinc deficiency is associated with type 2 diabetes. $^{15}$ The role of $\mathrm{Zn}$ (II) in the aggregation of hIAPP has been extensively studied, and it has been demonstrated in vitro that this metal ion delays the fibril formation of hIAPP by anchoring to His 18 and affecting the local conformation around this residue. ${ }^{16,17}$ Zinc promotes the formation of early aggregates and affects their morphology and density. ${ }^{18}$ The binding affinity of zinc for hIAPP is associated with a $K_{\mathrm{d}}=1.12$ $\mu \mathrm{M},{ }^{19}$ which is the same order of magnitude as the concentrations of zinc found in the extracellular space (15$25 \mu \mathrm{M}) .^{20}$

On the other hand, the role of the copper ion in amyloid formation of hIAPP is of particular interest given that serum copper levels in diabetic patients are higher in comparison to healthy people..$^{21-25}$ It has been proposed that the deregulation of copper homeostasis could play a role in $\mathrm{T} 2 \mathrm{D} .{ }^{26} \mathrm{Cu}$ (II) also inhibits hIAPP amyloid fibrillogenesis ${ }^{27}$ by binding to His 18 residue in hIAPP ${ }^{17,28,29}$ Recent studies have shown that copper inhibits the proteolytic action of insulin-degrading enzyme (IDE), which is responsible for hIAPP degradation. ${ }^{30}$ The proposed mechanism involves specific coordination of the metal ion to hIAPP, which could induce conformational changes in the peptide, rendering it unavailable for enzymatic hydrolysis. $^{31}$

The role of copper in the cytotoxicity of hIAPP has been explored by many groups in two aspects: (1) aggregation of the peptide and formation of oligomeric species in the presence of metal ion ${ }^{17,31-34}$ and (2) formation of reactive oxygen species (ROS) that could contribute to an increase of oxidative stress. $^{31,34,35}$ Viability assays have demonstrated that copper induces the formation of oligomeric species, increasing the cytotoxicity of hIAPP; ${ }^{31,33,34}$ while other studies reveal cell apoptosis caused by copper-peptide complexes. ${ }^{33,34}$ Recent findings by Lee and co-workers ${ }^{17}$ showed that $\mathrm{Cu}$ (II)containing oligomers of hIAPP form toxic aggregates with random coil conformations. On the other hand, experiments with catalase and electron paramagnetic resonance (EPR) spectroscopy demonstrated that copper can stimulate the formation of $\mathrm{H}_{2} \mathrm{O}_{2}$ during amyloid formation, promoting progressive degeneration of $\beta$-cells. ${ }^{35}$ It has been suggested that copper-induced formation of ROS can cause mitochondrial damage, leading to apoptosis. ${ }^{34}$

Overall, it is clear that copper ions impact the amyloid aggregation properties of hIAPP and may play a role in its toxicity and in the etiology of type 2 diabetes. Understanding the mechanisms involved requires a deeper knowledge of the structural details of the interaction of copper with hIAPP. Our previous study showed that the interaction of copper with the region encompassing His 18 and the residues that follow (1822) competes with the formation of $\beta$-rich structures and delays the formation of hIAPP fibrils. ${ }^{29}$ In the present work, we have performed a detailed spectroscopic study of $\mathrm{Cu}$ (II) binding to monomeric hIAPP, using EPR, nuclear magnetic resonance (NMR), electronic absorption and circular dichroism (CD) in the UV-vis region in combination with electronic structure calculations and Born-Oppenheimer molecular dynamics (BOMD). The construction of several variants of the hIAPP $(18-22)$ peptide have allowed the evaluation of the role of each residue in copper binding. Our study defines the nature of the coordination environment around the metal ion in the $\mathrm{Cu}(\mathrm{II})-\mathrm{hIAPP}$ complex, revealing that the amino acid residues involved in metal ion binding are also key residues for the formation of $\beta$-sheet structures and amyloid fibrils.

\section{EXPERIMENTAL SECTION}

Reagents. 9-Fluorenylmethoxycarbonyl (Fmoc) protected amino acids, Rink Amide MBHA resin, and ethyl (hydroxyimino)- 

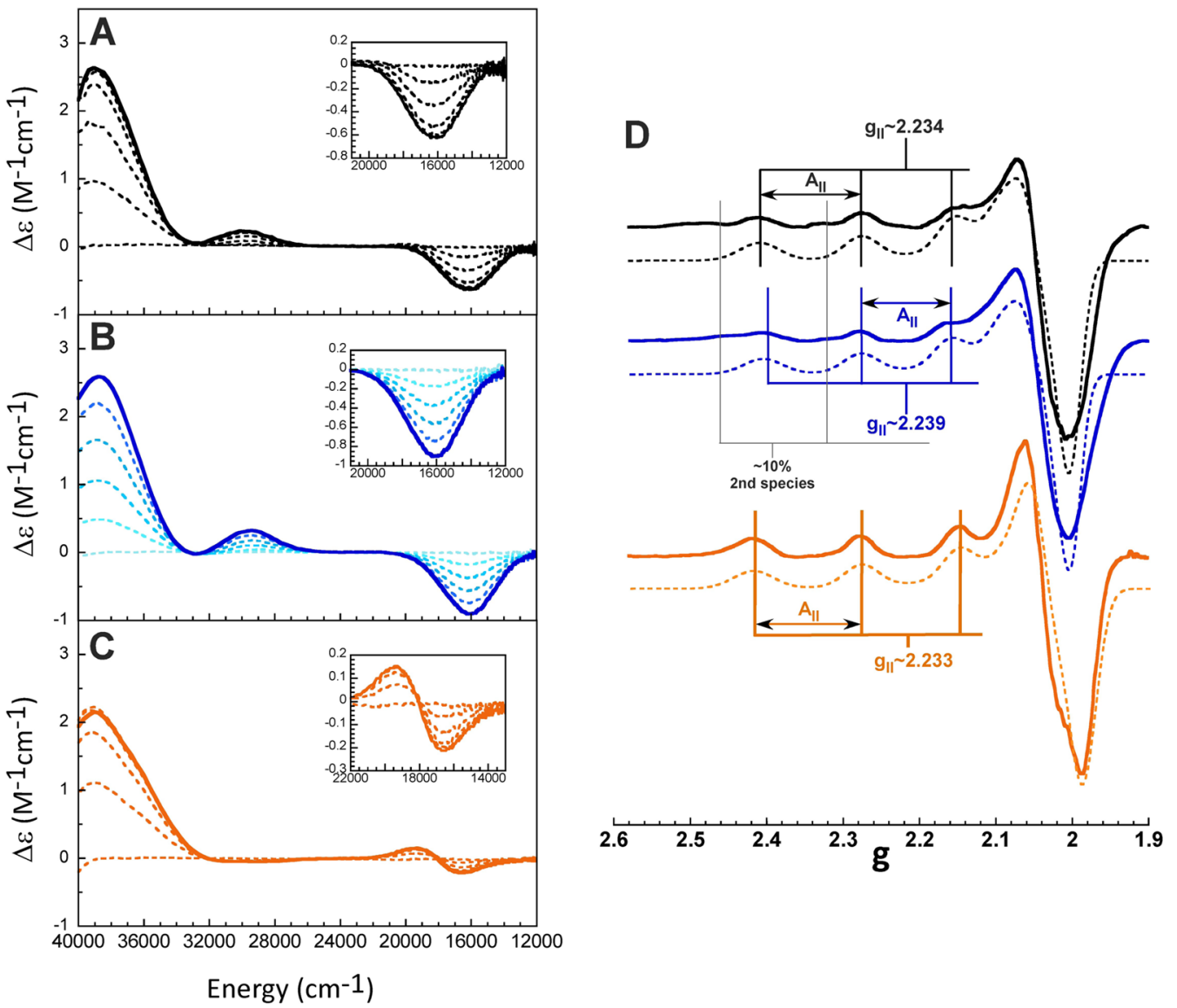

Figure 1. (A) Titration of hIAPP(15-22) (black) (A), hIAPP(18-22) (blue) (B), and hIAPP(15-22, S19P) (orange) (C) fragments with Cu(II) as followed by circular dichroism at $\mathrm{pH}$ 7.5. Spectra recorded after addition of $0,0.2,0.4,0.6,0.8$ equiv (dashed light color lines) and 1.0 equiv of $\mathrm{Cu}(\mathrm{II})$ (continuous dark line) are shown. (D) EPR spectra of the $\mathrm{Cu}$ (II) complexes with hIAPP(15-22) (black), hIAPP(18-22) (blue), hIAPP(15-22, S19P) (orange), after addition of 1.0 equiv of metal ion. Dotted lines correspond to the simulated EPR spectra, using parameters listed in Table $S 1$.

cyanoacetate (Oxyme Pure) for peptides synthesis were obtained from Novabiochem. The reagents and solvents were reagent grade from Sigma. HPLC-grade acetonitrile from Honeywell was used for peptide purification. Water was purified to a resistivity of $18 \mathrm{M} \Omega / \mathrm{cm}$ using Millipore Gradient deionized system. Deuterium oxide and deuterated 2-(N-morpholino)ethanesulfonic acid (MES) buffer were purchased from Sigma.

Peptide Synthesis and Purification. The peptides listed in Table 1 were synthesized by solid-phase synthesis and Fmoc strategy, using Fmoc-Rink amide resin. ${ }^{36,37}$ All peptides were acetylated at the amino terminus, and the carboxylic terminal was amidated. Crude peptides were purified by HPLC using a semipreparative C18 reversed phase column. Peptide purity was determined by analytical HPLC and was found to be $>95 \%$. Electrospray ionization mass spectrometry (ESIMS) determined the molecular weight of each peptide, and all purified products presented the expected molecular mass.

Preparation of Peptide Samples. Peptide solutions were prepared in a mixture of $20 \mathrm{mM}$ MES buffer and $20 \mathrm{mM} \mathrm{N}$ ethylmorpholine (NEM) buffer. For the $\mathrm{pH}$ titrations, the $\mathrm{pH}$ was varied every $0.25 \mathrm{pH}$ units by adding the necessary volume of $\mathrm{NaOH}$ or $\mathrm{HCl}$ solutions, and it was followed by $\mathrm{CD}$ spectroscopy. Peptide samples for EPR spectroscopy were prepared in the same buffer mixture with $50 \%$ glycerol to achieve adequate glassing. The addition of glycerol has no effect on the structure of the $\mathrm{Cu}(\mathrm{II})$-peptide complexes, as evaluated by absorption and $\mathrm{CD}$ spectroscopy for all buffer solutions and $\mathrm{pH}$ values used in this study. Final peptide concentrations were on the order of $0.4 \mathrm{mM}$. The NMR experiments were performed on $5.0 \mathrm{mM}\left({ }^{13} \mathrm{C} \mathrm{NMR}\right)$ peptide samples dissolved in $100 \%$ deuterium oxide. For 1D-IR experiments the samples were prepared in $100 \%$ deuterium oxide and $20 \mathrm{mM}$ of deuterated MES buffer with a final concentration of $0.3 \mathrm{mM}$. In each case the $\mathrm{pH}$ was adjusted to 7.5 with $\mathrm{NaOH}$ in $\mathrm{D}_{2} \mathrm{O}$.

UV-Visible Absorption and Circular Dichroism (CD) Spectroscopy. Room temperature absorption spectra were recorded using an Agilent 8453 diode array spectrometer, and $\mathrm{CD}$ spectra were acquired on a Jasco J-815 CD spectropolarimeter at room temperature. A $1 \mathrm{~cm}$ path length quartz cell was used, and spectra were recorded between 230 and $830 \mathrm{~nm}$ sampling points every $2 \mathrm{~nm}$ and with a scanning speed of $100 \mathrm{~nm} / \mathrm{min}$.

EPR Spectroscopy. X-band EPR spectra were collected using an EMX Plus Bruker System, with an ER 041 XG microwave bridge and an ER 4102ST cavity. The following conditions were used: microwave frequency, $9.4 \mathrm{GHz}$; microwave power, $10.02 \mathrm{~mW}$; modulation amplitude, $5 \mathrm{G}$; modulation frequency, $100 \mathrm{kHz}$; time constant, 327.68 $\mathrm{ms}$; conversion time, $82 \mathrm{~ms}$; and averaging over six scans. EPR spectra were recorded at $150 \mathrm{~K}$ using an ER4131VT variable temperature nitrogen system. EPR spectra were simulated with XSophe Computer Simulation Software Suite Version 1.1.4.

NMR Spectroscopy. NMR spectra were acquired on a Bruker 600 $\mathrm{MHz}$ Avance II equipped with cryogenically cooled triple resonance ${ }^{1} \mathrm{H}\left({ }^{13} \mathrm{C} /{ }^{15} \mathrm{~N}\right) \mathrm{TCl}$ probe at $298 \mathrm{~K}$. Proton and carbon resonances were assigned by $1 \mathrm{D}{ }^{1} \mathrm{H},{ }^{1} \mathrm{H}-{ }^{1} \mathrm{H}$ TOCSY, ${ }^{1} \mathrm{H}-{ }^{13} \mathrm{C} \mathrm{HMBC}$, and ${ }^{1} \mathrm{H}-{ }^{13} \mathrm{C}$ HSQC experiments. Chemical shifts were referenced to DSS as an internal standard. Proton spin-lattice relaxation rates were measured with a standard inversion recovery (1D-IR) Bruker pulse sequence. The $T_{1}$ values were determined by a three-parameter fit of peak intensities to the following equation: 


$$
I(t)=I_{0}\left[1-(1+B) \exp \left(-t / T_{1}\right)\right]
$$

where $B$ is a variable parameter that considers nonideal magnetization whose value is less than unity. ${ }^{38,39}$ The paramagnetic contributions of $\mathrm{Cu}(\mathrm{II})$ to the spin-lattice relaxation rate, $R_{1 \mathrm{p}}$, were calculated according to ${ }^{40}$

$$
R_{\mathrm{lp}}=R_{\mathrm{lobs}}-p_{\mathrm{f}} R_{\mathrm{lfree}}=\frac{p_{\mathrm{b}}}{R_{\mathrm{lb}}^{-1}+\tau_{\mathrm{M}}}
$$

where $\mathrm{f}$ and $\mathrm{b}$ refer to the free and metal-bound states, respectively, the $p$ 's are fractional populations of the peptide, $R_{1 \text { free }}$ and $R_{1 \mathrm{~b}}$ are the spin-lattice relaxation rates in the two environments, and $\tau_{\mathrm{M}}$ (the inverse of the off-rate kinetic constant) is the residence time of the peptide in the metal coordination sphere. $R_{1 \mathrm{~b}}\left(1 / T_{1 \mathrm{~b}}\right)$ is accounted for by the Solomon equation describing the dipole-dipole nuclear spinelectron spin interaction, here reported for systems with $S=1 / 2:^{40,41}$

$$
\begin{aligned}
R_{\mathrm{lb}}= & \frac{1}{10}\left(\frac{\mu_{0}}{4 \pi}\right)^{2} \frac{2 \hbar^{2} \gamma_{\mathrm{I}}^{2} \gamma_{\mathrm{S}}^{2}}{r^{6}}\left\{\frac{\tau_{\mathrm{C}}}{1+\left(\omega_{\mathrm{I}}-\omega_{\mathrm{S}}\right)^{2} \tau_{\mathrm{C}}^{2}}+\frac{3 \tau_{\mathrm{C}}}{1+\omega_{\mathrm{I}}^{2} \tau_{\mathrm{C}}^{2}}\right. \\
& \left.+\frac{6 \tau_{\mathrm{C}}}{1+\left(\omega_{\mathrm{I}}-\omega_{\mathrm{S}}\right)^{2} \tau_{\mathrm{C}}^{2}}\right\}
\end{aligned}
$$

where $\mu_{0}$ is the permeability of the vacuum, $\gamma_{\mathrm{I}}$ and $\gamma_{\mathrm{S}}$ are the nuclear and electron magnetogyric ratios, respectively, $\hbar$ is the reduced Planck constant, $\omega_{\mathrm{I}}$ and $\omega_{\mathrm{S}}$ are the nuclear and electron Larmor frequencies, respectively, $r$ is the proton-metal distance, and $\tau_{\mathrm{C}}$ is the effective correlation time.

Acquisition, processing, and visualization of the NMR spectra were performed using TOPSPIN 3.2 (Bruker) and CcpNmr Analysis 2.4.2. ${ }^{42}$

Theoretical Studies. The gas phase models for the $\mathrm{Cu}(\mathrm{II})$ hIAPP (18-22) complex were constructed with Molden $^{43}$ using the full peptide fragment $18-22$ (total number of atoms was 75 ) and optimized with TeraChem, ${ }^{44}$ using spin-unrestricted Kohn-Sham theory within the linear combination of Gaussian-type orbitals to solve the Kohn-Sham equations. For all models, a spin multiplicity of two was imposed, employing the $\mathrm{PBE}^{45}$ exchange-correlation functional and DZVP ${ }^{46}$ basis set as implemented in the deMon $2 \mathrm{k}^{47}$ code. Explicit solvation was included by adding four water molecules to each model and reoptimizing the structures. NVT BOMD were performed with spherical boundary conditions using TeraChem code default options, namely, a time step of $1 \mathrm{fs}$ was used to integrate the equations of motion, the temperature was controlled at $300 \mathrm{~K}$ by rescaling at each step the velocities of the atoms. The BOMD simulation was carried out for 60 ps. From this time window, a local search for minimum energy conformers at $0 \mathrm{~K}$ was performed, which made it possible to identify the lowest energy conformers through this sampling. We then performed two regular BOMD simulations of 20 ps (releasing the spherical boundary conditions) for the lowest energy optimized model, rescaling the temperature every 50 integration steps. Afterward, the first 3 ps of the simulation were discarded, and the energy minima were reoptimized to be used as a starting point for a second BOMD simulation with total of time length of 20 ps. This procedure was used because the system remained with the same coordination pattern along the first BOMD simulation. Selected points from this last BOMD sampling were used for successive geometry optimizations and spectroscopic simulation.

EPR parameters for selected models were calculated employing the eprnmr module implemented in the 3.0.2 version of the ORCA ${ }^{48}$ electronic structure code. For such calculations, the hybrid exchangecorrelation functional PBE0 $0^{49,50}$ was used; a DGAUSS basis set was used for main row atoms, and the Core Property basis ${ }^{51}$ was used for the copper atom. It is important to mention that a special grid and an integral accuracy of seven for copper (as reported in the Orca manual) were also used. In all cases the center of electric charge was used as a gauge origin and the orbital energy window used was $(-1000,1000)$ hartree. Although the models already included four explicit water molecules, the COSMO implicit solvation, as implemented in ORCA, was also used. Spin-orbit coupling was requested with SOCflags $1,3,3,1$.

\section{RESULTS AND ANALYSIS}

hIAPP(18-22) as a Model for $\mathrm{Cu}(\mathrm{II})$ Binding to Monomeric hIAPP. $\mathrm{Cu}$ (II) coordination to hIAPP has been previously studied using the $\operatorname{hIAPP}(15-22)$ fragment. A titration of this peptide with $\mathrm{Cu}(\mathrm{II})$, followed by $\mathrm{CD}$, shows the growth of signals associated with the hIAPP(15-22)$\mathrm{Cu}$ (II) complex (Figure $1 \mathrm{~A}$ ), namely, a negative ligand field transition as $16200 \mathrm{~cm}^{-1}\left(\Delta \varepsilon=-0.71 \mathrm{M}^{-1} \mathrm{~cm}^{-1}\right)$, and three ligand-to-metal charge transfer (LMCT) bands: a positive band at $29800 \mathrm{~cm}^{-1}\left(\Delta \varepsilon=0.14 \mathrm{M}^{-1} \mathrm{~cm}^{-1}\right)$, a negative band at $32400 \mathrm{~cm}^{-1}$ with very low intensity $\left(\Delta \varepsilon=-0.024 \mathrm{M}^{-1} \mathrm{~cm}^{-1}\right)$, and a positive band at $39000 \mathrm{~cm}^{-1}$ with high intensity $(\Delta \varepsilon=$ $\left.2.64 \mathrm{M}^{-1} \mathrm{~cm}^{-1}\right)$. These LMCT bands have been assigned to the deprotonated backbone amide $\mathrm{N}^{-}$, and the imidazole $\pi_{1}$ and $\pi_{2}$ to $\mathrm{Cu}(\mathrm{II}) \mathrm{LMCT}$ transitions, respectively. ${ }^{29}$ Previous work supports the notion that this complex involves coordination to the C-terminal residues. ${ }^{29}$ Here, we have studied $\mathrm{Cu}$ (II) binding to hIAPP(15-22 S19P), where the Pro residue at position 19 would prevent coordination of the metal ion toward the C-terminal. When a solution of hIAPP(15-22 S19P) was titrated with $\mathrm{Cu}(\mathrm{II})$ at $\mathrm{pH} 7.5$, all $\mathrm{CD}$ signals were saturated at 1.0 equiv of $\mathrm{Cu}(\mathrm{II})$ indicating a 1:1 molar stoichiometry (Figure 1C). Two ligand field transitions become evident: a negative band at $16580 \mathrm{~cm}^{-1}\left(\Delta \varepsilon=-0.21 \mathrm{M}^{-1} \mathrm{~cm}^{-1}\right)$ and a positive band at $19300 \mathrm{~cm}^{-1}\left(\Delta \varepsilon=0.15 \mathrm{M}^{-1} \mathrm{~cm}^{-1}\right)$, while LMCT bands are observed in the region above $32000 \mathrm{~cm}^{-1}$, possibly corresponding to imidazole to $\mathrm{Cu}$ (II) LMCT transitions. Clearly, the Cu(II)-hIAPP(15-22 S19P) complex displays a very different $\mathrm{CD}$ spectrum than that of the $\mathrm{Cu}(\mathrm{II})-$ hIAPP(15-22) complex (Figure 1A). Consistently, the EPR spectrum of the $\mathrm{Cu}$ (II)-hIAPP(15-22 S19P) complex displays very different $A_{\|}$and $g_{\|}$values, as compared to those associated with the $\mathrm{Cu}(\mathrm{II})-\mathrm{hIAPP}(15-22)$ complex (Figure $1 \mathrm{D}$ and Table 1). Thus, by blocking the backbone amide of Ser19 and inducing a turn on the backbone with a Pro residue, coordination of $\mathrm{Cu}$ (II) toward the C-terminal is prevented, and a $\mathrm{Cu}(\mathrm{II})$-peptide complex with a different coordination environment is formed. This is consistent with the notion that $\mathrm{Cu}$ (II) coordination to hIAPP(15-22) involves residues that follow His 18 in the sequence. If this is the case, then the hIAPP(18-22) fragment would be a good model to study $\mathrm{Cu}$ (II) coordination to monomeric hIAPP. $\mathrm{Cu}$ (II) binding to the hIAPP $(18-22)$ fragment was studied by titrating the peptide with $\mathrm{Cu}(\mathrm{II})$ at $\mathrm{pH} 7.5$, followed by $\mathrm{CD}$ (Figure 1B). The CD signals are saturated at 1.0 equiv of $\mathrm{Cu}(\mathrm{II})$ indicating a 1:1 molar stoichiometry as in the case of the $\operatorname{hIAPP}(15-22)$ fragment (Figure 1A, black spectra). The CD spectrum of the $\mathrm{Cu}(\mathrm{II})-\mathrm{hIAPP}(18-22)$ complex shows one $\mathrm{d}-\mathrm{d}$ negative band at $16050 \mathrm{~cm}^{-1}\left(\Delta \varepsilon=-0.89 \mathrm{M}^{-1} \mathrm{~cm}^{-1}\right)$ and three transitions that correspond to LMCT bands: a positive band at 29460 $\mathrm{cm}^{-1}\left(\Delta \varepsilon=0.32 \mathrm{M}^{-1} \mathrm{~cm}^{-1}\right)$ that corresponds to deprotonated backbone amide $\mathrm{N}^{-}$to $\mathrm{Cu}(\mathrm{II})$ LMCT, a negative band at $32700 \mathrm{~cm}^{-1}$ with very low intensity $\left(\Delta \varepsilon=-0.02 \mathrm{M}^{-1} \mathrm{~cm}^{-1}\right)$, and a positive band at $38840 \mathrm{~cm}^{-1}$ with high intensity $(\Delta \varepsilon=$ $\left.2.60 \mathrm{M}^{-1} \mathrm{~cm}^{-1}\right)$, corresponding respectively to a $\pi_{1}$ and a $\pi_{2}$ to $\mathrm{Cu}$ (II) LMCT bands arising from the interaction of the His 18 imidazole with the metal ion. ${ }^{52,53}$ Clearly, the CD spectrum of the $\mathrm{Cu}(\mathrm{II})-\mathrm{hIAPP}(18-22)$ complex is practically identical to that of the $\mathrm{Cu}(\mathrm{II})-\mathrm{hIAPP}(15-22)$ complex. Moreover, their EPR spectra display very similar $A_{\|}$and $g_{\|}$values: $A_{\|}=158 \times$ 

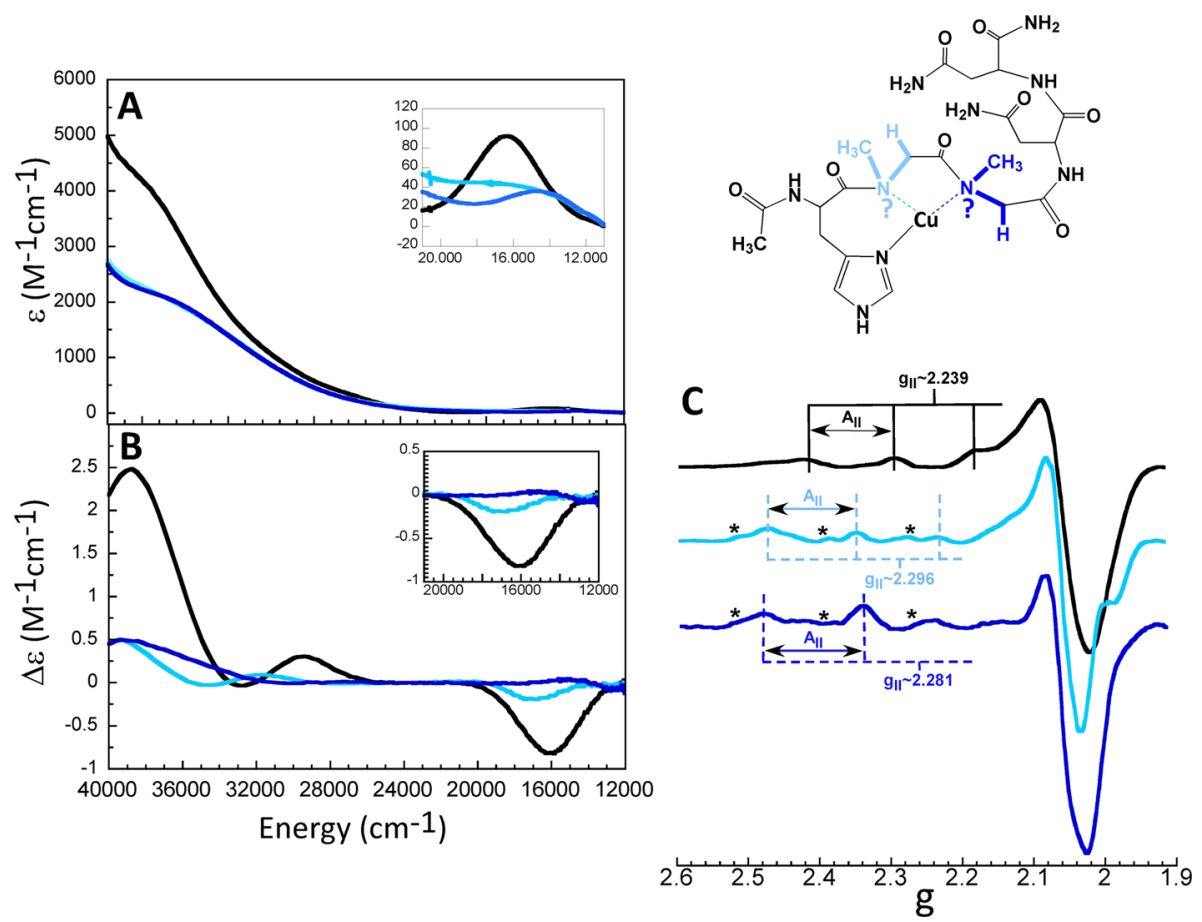

Figure 2. UV-vis absorption (A), CD (B), and EPR (C) spectra of Cu(II) complexes with hIAPP(18-22) (black), hIAPP (18-22, S19Sar) (light blue), and hIAPP (18-22, S20Sar) (dark blue) with 1.0 equiv of $\mathrm{Cu}(\mathrm{II})$ and $\mathrm{pH}$ 7.5. The asterisks in EPR spectra indicate the signals of $\mathrm{Cu}$ (II) in solution. The scheme at the upper right represents the variants with sarcosine where the $\mathrm{N}$ - from backbone amide is blocked with a methyl group.
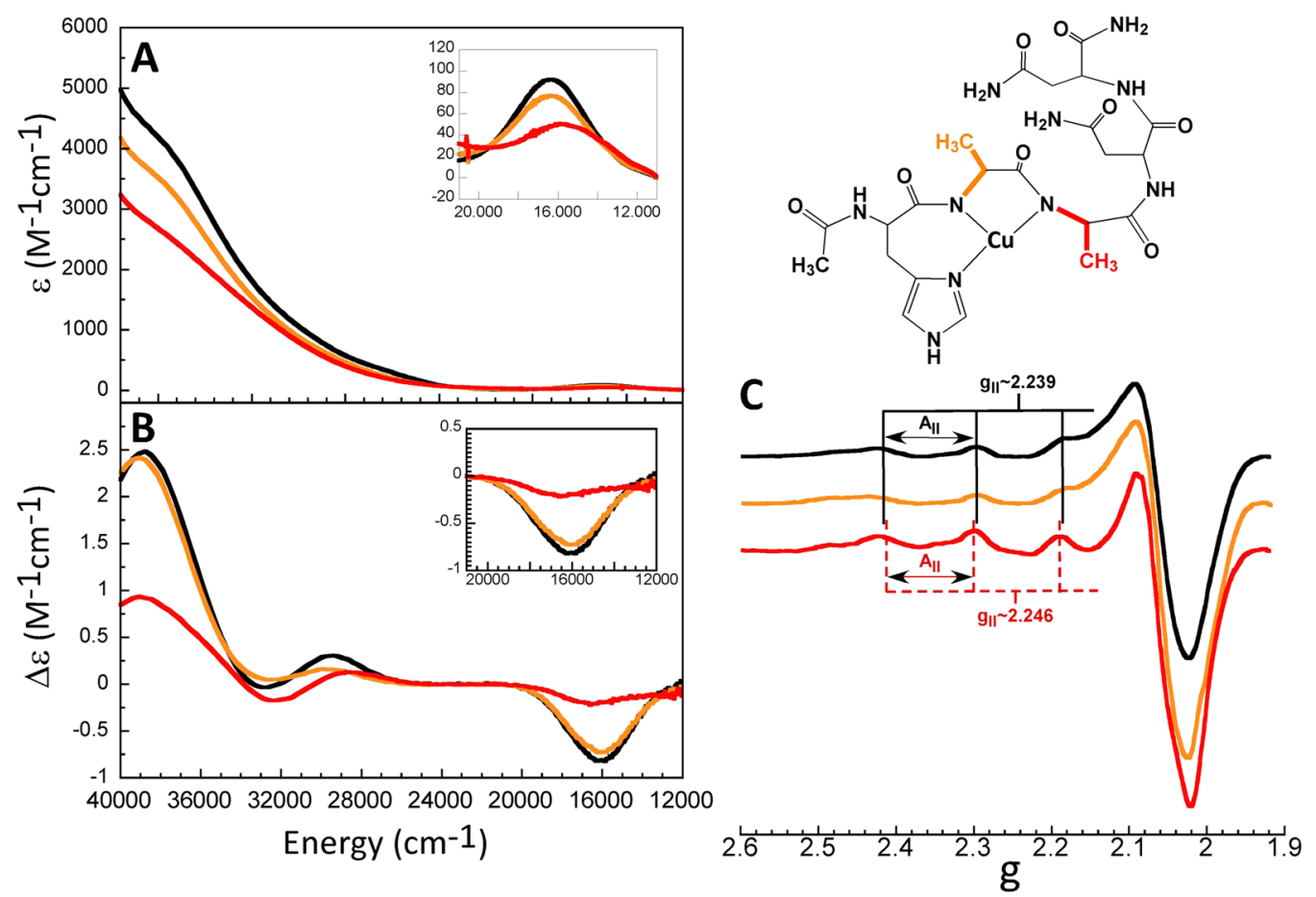

Figure 3. UV-vis absorption (A), CD (B), and EPR (C) spectra of Cu(II) complexes with hIAPP(18-22) (black), hIAPP (18-22, S19A) (orange), and hIAPP (18-22, S20A) (red) with 1.0 equiv of $\mathrm{Cu}(\mathrm{II})$ and $\mathrm{pH}$ 7.5. The scheme at the upper right represents the variants with alanine where the $-\mathrm{CH}_{2}-\mathrm{OH}$ group from serine has been replaced with $-\mathrm{CH}_{3}$.

$10^{-4} \mathrm{~cm}^{-1}$ and $g_{\|}=2.239$ for the $\mathrm{Cu}(\mathrm{II})-\mathrm{hIAPP}(18-22)$ complex, and $A_{\|}=164 \times 10^{-4} \mathrm{~cm}^{-1}$ and $g_{\|}=2.234$ for the $\mathrm{Cu}$ (II)-hIAPP(15-22) complex (Figure 1D, Tables 1 and S1), which correspond to an equatorial coordination mode with three nitrogens and one oxygen ligand, according to Peisach and Blumberg correlations. ${ }^{54}$ In both cases, a small amount
$(<10 \%)$ of a second species with $A_{\|}=168 \times 10^{-4} \mathrm{~cm}^{-1}$ and $g_{\|}$ $=2.276$ also becomes evident in the EPR spectrum; given the $\mathrm{p} K_{\mathrm{a}}$ values associated with the $\mathrm{Cu}(\mathrm{II})-\mathrm{hIAPP}(18-22)(6.28 \pm$ 0.01 , Figure $\mathrm{S} 1$ ) and the $\mathrm{Cu}(\mathrm{II})-\mathrm{hIAPP}(15-22)$ complex $(6.23 \pm 0.13),{ }^{29}$ the second species likely corresponds to the protonated form of each complex. 


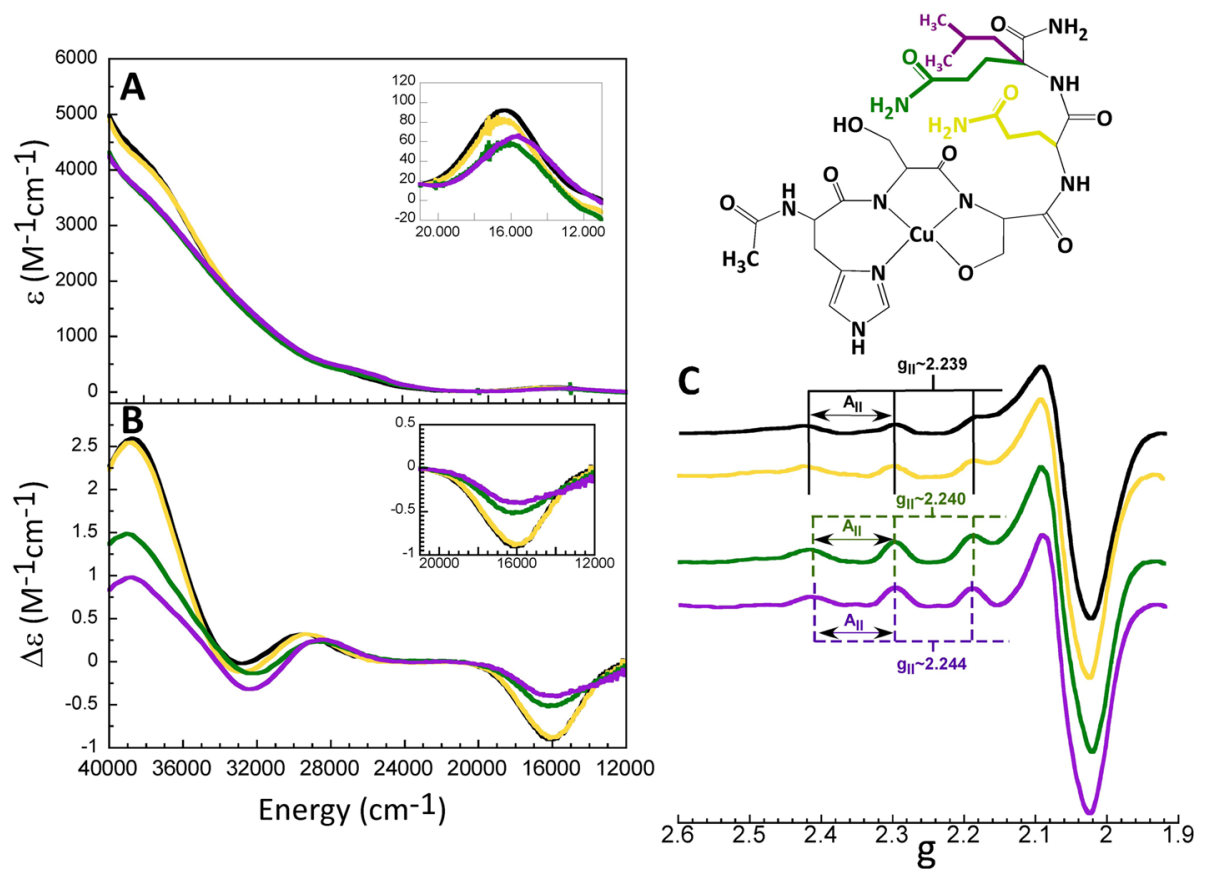

Figure 4. UV-vis absorption (A), CD (B), and EPR (C) spectra of Cu(II) complexes with hIAPP(18-22) (black), hIAPP (18-22, N21Q) (yellow), hIAPP (18-22, N22Q) (green), and hIAPP(18-22, N22L) (purple) with 1.0 equiv of $\mathrm{Cu}(\mathrm{II})$ and $\mathrm{pH}$ 7.5. The scheme at the upper right represents the variants with glutamine where the $-\mathrm{CH}_{2}-\mathrm{CO}-\mathrm{NH}_{2}$ group from asparagine has been modified as $-\mathrm{CH}_{2}-\mathrm{CH}_{2}-\mathrm{CO}-\mathrm{NH}_{2}$ (yellow and green) and one variant with the R-group of leucine $-\mathrm{CH}_{2}-\mathrm{CH}-\left(\mathrm{CH}_{3}\right)_{2}$ (purple) in asparagine 22 .

Overall, these results indicate that the $\operatorname{hIAPP}(18-22)$ peptide is an adequate model that reproduces the $\mathrm{Cu}$ (II) coordination features of the longer peptide hIAPP $(15-22)$. Our findings are consistent with a study by $\mathrm{Li}$ and co-workers ${ }^{28}$ showing by laser ablation electrospray ionization ion mobility separation mass spectrometry (LAESI-IMS-MS) that $\mathrm{Cu}$ (II) exhibits strong association with these residues -HSSNN- (1822) of hIAPP.

Identifying the Backbone Amides Involved in $\mathrm{Cu}(\mathrm{II})$ Binding to hIAPP(18-22). In order to further characterize the role of backbone amide groups in the coordination of $\mathrm{Cu}(\mathrm{II})$ to hIAPP(18-22), two hIAPP(18-22) variants were synthesized: hIAPP(18-22 S19Sar) and hIAPP(18-22 S20Sar), where Sar corresponds to sarcosine, i.e., $\mathrm{N}$ methylglycine. In these peptides, the backbone amide is blocked by the methyl group at the position of each sarcosine (scheme in Figure 2). The UV-vis electronic absorption (A), $\mathrm{CD}$ (B), and EPR (C) spectra of the $\mathrm{Cu}$ (II) complexes with these Ser to Sar variants are compared to those of the $\mathrm{Cu}(\mathrm{II})-$ hIAPP $(18-22)$ complex in Figure 2. The UV-vis absorption spectrum of the $\mathrm{Cu}(\mathrm{II})-\mathrm{hIAPP}(18-22)$ complex (black line) displays a ligand field band at $\sim 16300 \mathrm{~cm}^{-1}\left(\varepsilon=91 \mathrm{M}^{-1}\right.$ $\left.\mathrm{cm}^{-1}\right)$, while this transition is shifted to $\sim 14400 \mathrm{~cm}^{-1}(\varepsilon=36$ $\mathrm{M}^{-1} \mathrm{~cm}^{-1}$ ) for the $\mathrm{Cu}(\mathrm{II})-\mathrm{hIAPP}(18-22$ S20Sar) complex (dark blue line), and the absorption spectrum of the $\mathrm{Cu}(\mathrm{II})-$ hIAPP(18-22 S19Sar) complex (light blue line) has such low intensity that it is not possible to determine the energy for the ligand field transitions. The drastic effects of the Ser to Sar substitutions are also evident by $\mathrm{CD}$ (Figure 2B): the spectra for the $\mathrm{Cu}(\mathrm{II})-\mathrm{hIAPP}(18-22$ S19Sar) and $\mathrm{Cu}(\mathrm{II})-\mathrm{hIAPP}-$ (18-22 S20Sar) complexes have such low intensity that their transitions are hard to identify. The low intensity of the CD spectra for the Ser to Sar variants indicates that either the chirality of the complexes has changed (as in the case of the formation of a very different $\mathrm{Cu}$ (II) complex) and/or the affinity of the peptide for $\mathrm{Cu}$ has decreased (since unbound $\mathrm{Cu}$ (II) would not contribute to $\mathrm{CD}$ intensity). Consistently, the EPR spectra for these variants indicate the presence of free $\mathrm{Cu}(\mathrm{II})$ in solution (indicated as asterisks in Figure 2C), and the formation of a $\mathrm{Cu}(\mathrm{II})$ complex with $A_{\|}$and $g_{\|}$values that are very different from those of the $\mathrm{Cu}(\mathrm{II})-\mathrm{hIAPP}(18-22)$ complex (Figure 2C, Tables 1 and S1). In both cases, the Ser to Sar substitutions yielded $\mathrm{Cu}(\mathrm{II})$ complexes with more oxygen-rich equatorial coordination modes ( $2 \mathrm{~N} 2 \mathrm{O} / 1 \mathrm{~N} 3 \mathrm{O})$. Altogether, these results indicate that the backbone amide groups of Ser19 and Ser20 participate in the coordination sphere of the $\mathrm{Cu}(\mathrm{II})-\mathrm{hIAPP}(18-22)$ complex.

Evaluating the Role of Hydroxyl Groups of Ser19 and Ser20. The participation of the hydroxyl groups of Ser19 and Ser20 in $\mathrm{Cu}$ (II) binding was evaluated by replacing Ser19 or Ser20 with Ala residues (Scheme in Figure 3). The UV-vis electronic absorption and CD spectra of $\mathrm{Cu}(\mathrm{II})-\mathrm{hIAPP}(18-22$ S19A) (Figure 3A,B, orange line) are practically identical to those of the $\mathrm{Cu}(\mathrm{II})-\mathrm{hIAPP}(18-22)$ complex (black line), while significant changes are observed for the $\mathrm{Cu}(\mathrm{II})-$ hIAPP(18-22 S20A) complex (red line). Specifically, the ligand field band for the $\mathrm{Cu}(\mathrm{II})-\mathrm{hIAPP}(18-22$ S20A) complex (red line) is shifted to lower energy in the absorption spectrum (Figure 3A), as compared to that of the Cu(II)-hIAPP(1822) complex (black line), while the $\mathrm{CD}$ intensity of all transitions is significantly decreased (Figure 3B). Consistently, the EPR spectra of the $\mathrm{Cu}(\mathrm{II})-\mathrm{hIAPP}(18-22)$ complex (black spectrum) and $\mathrm{Cu}(\mathrm{II})-\mathrm{hIAPP}(18-22 \mathrm{~S} 19 \mathrm{~A})$ complex (orange spectrum, Figure $3 \mathrm{C}$ ) are practically identical, while that for the $\mathrm{Cu}$ (II)-hIAPP(18-22 S20A) complex (red spectrum) displays different EPR parameters. Overall, these results indicate that the hydroxyl group from Ser19 is not participating in copper coordination, while that of Ser20 does contribute to $\mathrm{Cu}$ (II) binding at this site. 

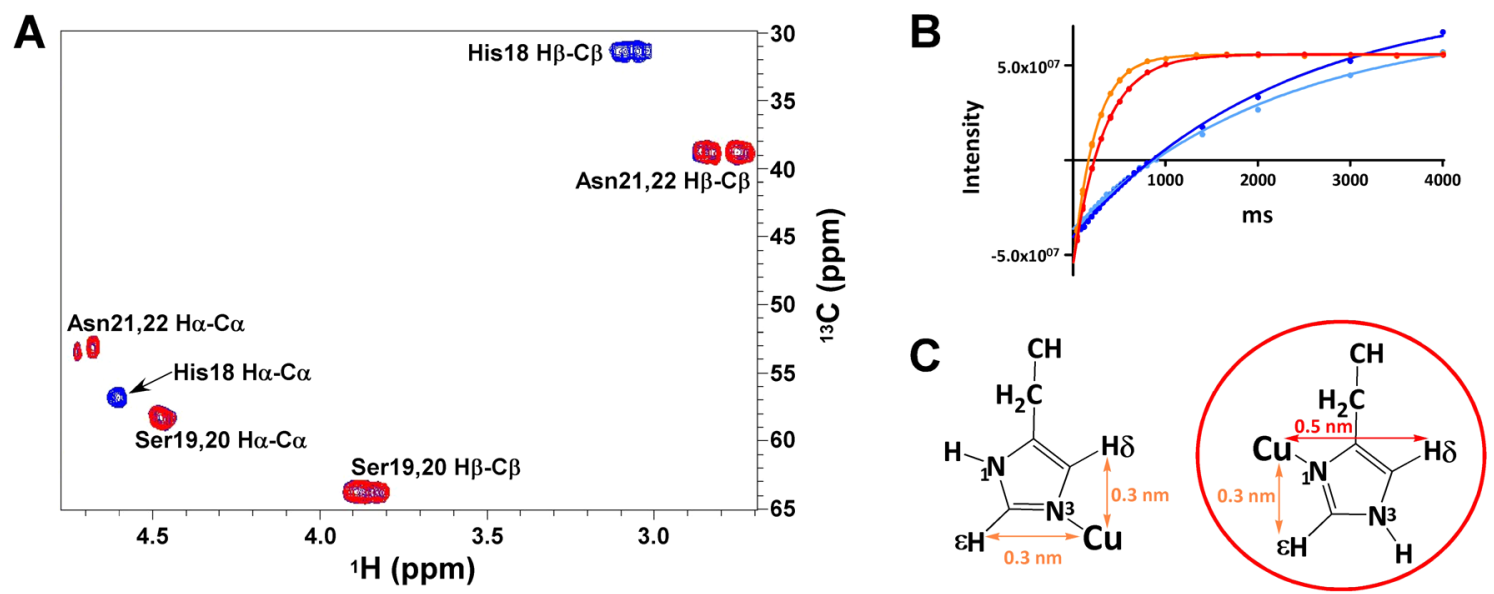

Figure 5. (A) Overlaid ${ }^{1} \mathrm{H}-{ }^{13} \mathrm{C}$ HSQC spectra of hIAPP(18-22) in the absence (blue) and presence (red) of 0.2 equiv of $\mathrm{Cu}$ (II) in the aliphatic region. (B) Fits from proton spin-lattice relaxation rates by $1 \mathrm{D}$-IR experiments of $\mathrm{H} \varepsilon$ and $\mathrm{H} \delta$ of imidazole ring from His 18 in the absence and presence of $\mathrm{Cu}(\mathrm{II})$. The free species correspond to $\mathrm{H} \varepsilon$ (light blue) and $\mathrm{H} \delta$ (dark blue). The bound species to 0.02 equiv of $\mathrm{Cu}$ (II) correspond to $\mathrm{H} \varepsilon$ (orange) and $\mathrm{H} \delta$ (red). Schema (C) represents the two possibilities of $\mathrm{Cu}$ (II) binding to N1 or N3 from imidazole and the distances in each case. Our results show that $\mathrm{Cu}(\mathrm{II})$ is binding to $\mathrm{N} 1$ represented by a red circle.

Evaluating the Role of Asparagines 21 and 22. In order to evaluate the role of Asn residues 21 and 22 in $\mathrm{Cu}(\mathrm{II})$ coordination, the $\mathrm{N} 21 \mathrm{Q}, \mathrm{N} 22 \mathrm{Q}$ and $\mathrm{N} 22 \mathrm{~L}$ variants of hIAPP (18-22) were prepared. In the first two, the R-group from asparagine, $-\mathrm{CH}_{2}-\mathrm{CO}-\mathrm{NH}_{2}$, has been replaced by the longer group, $-\mathrm{CH}_{2}-\mathrm{CH}_{2}-\mathrm{CO}-\mathrm{NH}_{2}$, and in the $\mathrm{N} 22 \mathrm{~L}$ variant the R-group of asparagine 22 has been replaced by an aliphatic group $-\mathrm{CH}_{2}-\mathrm{CH}-\left(\mathrm{CH}_{3}\right)_{2}$ as shown in the scheme of Figure 4. Overall, the UV-vis absorption and $\mathrm{CD}$ spectra of the $\mathrm{Cu}(\mathrm{II})-$ hIAPP $(18-22)$ complex and the N21Q variant are practically identical (Figure 4A,B), while their EPR spectra display very similar EPR parameters (Figure 4C, Table 1), clearly indicating that Asn21 does not participate in $\mathrm{Cu}(\mathrm{II})$ coordination to the peptide. On the other hand, the absorption and CD spectra of the $\mathrm{Cu}(\mathrm{II})-\mathrm{hIAPP}(18-22 \mathrm{~N} 22 \mathrm{Q})$ (green lines) and the $\mathrm{Cu}(\mathrm{II})-\mathrm{hIAPP}(18-22 \mathrm{~N} 22 \mathrm{~L})$ (purple lines) complexes display decreased intensity of their $\mathrm{d}-\mathrm{d}$ band at $16200 \mathrm{~cm}^{-1}$ and LMCT $\pi_{2}$ transition at $39030 \mathrm{~cm}^{-1}$, while a small shift is evident at the LMCT transitions with respect to those of the $\mathrm{Cu}(\mathrm{II})-\mathrm{hIAPP}(18-22)$ (black line). Consistently, the EPR spectra of the complexes with Asn22 substitutions show changes in their $A_{\|}$and $g_{\|}$values, most notably for the N22L variant (Figure 4C, Tables 1 and S1). Overall, these results suggest that Asn 22 may play a role in $\mathrm{Cu}(\mathrm{II})$ coordination to hIAPP(18-22); however, the effects of its substitution for a noncoordinating residue in the spectroscopic features of the complex are mild, as compared to those observed upon the Ser to Sar or S20A substitutions. Thus, the role of Asn22 in $\mathrm{Cu}$ (II) binding to hIAPP(18-22) might be as an axial ligand or as part of the second sphere coordination shell.

$\mathrm{Cu}(\mathrm{II})$ Binding to hIAPP(18-22) as Probed by NMR. ${ }^{1} \mathrm{H}-{ }^{13} \mathrm{C}$ nuclear magnetic resonance (NMR) signals were assigned using $1 \mathrm{D}{ }^{1} \mathrm{H},{ }^{1} \mathrm{H}-{ }^{1} \mathrm{H}$ TOCSY, ${ }^{1} \mathrm{H}-{ }^{13} \mathrm{C} \mathrm{HSQC}$, and $\mathrm{HMBC}$ spectra. Figure 5A shows the overlaid aliphatic region of the ${ }^{1} \mathrm{H}-{ }^{13} \mathrm{C}$ HSQC spectra of hIAPP $(18-22)$ in the absence (blue) and presence (red) of 0.2 equiv of $\mathrm{Cu}(\mathrm{II})$. The paramagnetic effect of $\mathrm{Cu}(\mathrm{II})$ causes broadening of the signals due to relaxation enhancements, ${ }^{55}$ and the most affected ones are the $\mathrm{H} \beta-\mathrm{C} \beta$ and $\mathrm{H} \alpha-\mathrm{C} \alpha$ of His 18, which disappear completely upon addition of $\mathrm{Cu}(\mathrm{II})$, indicating that His18 is the main anchoring site for $\mathrm{Cu}(\mathrm{II})$. To gain further insight into the structural features of $\mathrm{Cu}$ (II) binding to hIAPP(18-22), proton spin-lattice relaxation rates of the imidazole protons $\mathrm{H} \varepsilon$ and $\mathrm{H} \delta$ were measured to determine to which nitrogen, N1 or $\mathrm{N} 3$ of His 18 coordinates $\mathrm{Cu}(\mathrm{II}) .{ }^{56}$ Figure $5 \mathrm{~B}$ displays the fits for $T_{1}$ of $\mathrm{H} \varepsilon$ (light blue) and $\mathrm{H} \delta$ (dark blue) for the free peptide, and those for the bound species after addition of 0.02 equiv of $\mathrm{Cu}(\mathrm{II})\left(\mathrm{H} \varepsilon\right.$ (orange) and $\mathrm{H} \delta$ (red)). The ${ }^{1} \mathrm{H}$ NMR spectra given in Figure $\mathrm{S} 2$ shows the broadening effect on both signals after addition of $\mathrm{Cu}(\mathrm{II})$. Table 2 shows the parameters

Table 2. Parameters from 1D-IR Experiment of the Protons $\mathrm{H} \varepsilon$ and $\mathrm{H} \delta$ of His 18

\begin{tabular}{ccccccl} 
& $T_{1 \text { free }}$ & $T_{1 \text { bound }}$ & $R_{1 \mathrm{~b} \text { free }}$ & $R_{\mathrm{lb} \text { bound }}$ & $R_{\mathrm{lp}}$ & \multicolumn{1}{c}{ dist $(\mathrm{nm})$} \\
$\mathrm{H} \delta$ & 2.2 & 0.334 & 0.455 & 2.994 & 2.549 & 0.506 \\
$\mathrm{H} \varepsilon$ & 2.2 & 0.239 & 0.455 & 4.184 & 3.739 & 0.3 (fixed) \\
\hline
\end{tabular}

$T_{1}, R_{1 \mathrm{~b}}, R_{\mathrm{lp}}$, and the distance for the protons $\mathrm{H} \varepsilon$ and $\mathrm{H} \delta$ to $\mathrm{Cu}(\mathrm{II})$ ion. $\tau_{\mathrm{M}}=1 / k_{\text {off }}$ was calculated using a fixed distance of $0.3 \mathrm{~nm}$ from $\mathrm{Cu}$ (II) to $\mathrm{H} \varepsilon^{56}$ of His 18, obtaining a value of 5.2 ms. A global correlation time $\tau_{\mathrm{C}}$ of $0.4 \mathrm{~ns}$ was assumed. ${ }^{57}$ Figure $5 \mathrm{C}$ compares the two possibilities of binding of $\mathrm{Cu}(\mathrm{II})$ to $\mathrm{N} 1$ or $\mathrm{N} 3$, where the distance of $0.3 \mathrm{~nm}$ from $\mathrm{Cu}$ (II) to $\mathrm{H} \varepsilon$ is fixed. These results clearly show that $\mathrm{Cu}(\mathrm{II})$ is binding to $\mathrm{N} 1$ of imidazole ring of His 18.

Figure 6 shows the overlaid $1 \mathrm{D}{ }^{13} \mathrm{C}$ NMR spectra of hIAPP $(18-22)$ in the absence (blue) and presence (red) of 0.4 equiv of $\mathrm{Cu}(\mathrm{II})$. Upon addition of the metal ion, the signals for $\mathrm{CO}, \mathrm{C}_{\text {aromatic }} \mathrm{C} \alpha$, and $\mathrm{C} \beta$ from His 18 disappear completely, while all other signals display decreased intensity. The intensity of the signal of the Asn22 seems to be more affected than that of Asn21, consistent with the notion that Asn22 might be involved in $\mathrm{Cu}$ (II) coordination (vide supra).

Theoretical Studies of Cu(II) Binding to hIAPP(18-22). On the basis of our spectroscopic results, it becomes clear that the three nitrogens in the equatorial coordination sphere of $\mathrm{Cu}$ bound to hIAPP $(18-22)$ are provided by the imidazole nitrogen N1 of His18, the deprotonated amides of Ser19 and Ser20, and an oxygen-based ligand, which likely corresponds to the $\mathrm{OH}$ group of Ser20, while Asn22 might also play a role as an axial ligand. In order to shed light into the nature of the 

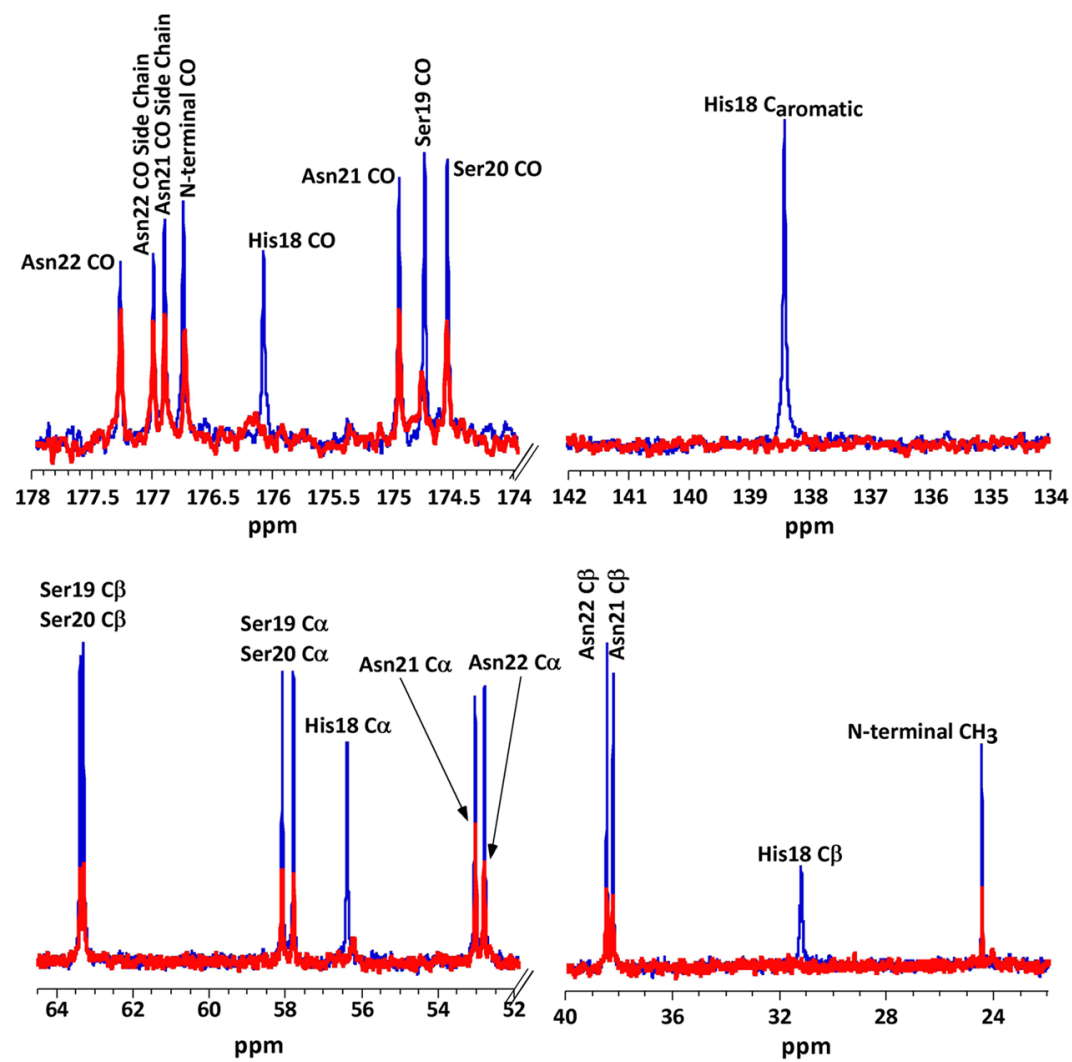

Figure 6. Overlaid $1 \mathrm{D}{ }^{13} \mathrm{C}$ NMR spectra of hIAPP(18-22) in the absence (blue) and presence (red) of 0.4 equiv of $\mathrm{Cu}(\mathrm{II}) . \mathrm{CO}, \mathrm{C}$ aromatic $\mathrm{C} \alpha$, and $\mathrm{C} \beta$ from His18 disappear completely upon addition $\mathrm{Cu}(\mathrm{II})$. The arrows show each $\mathrm{C} \alpha$ from Asn 21 and 22.

oxygen-based equatorial ligand and the role of Asn22 in $\mathrm{Cu}$ coordination, several models of the Cu(II)-hIAPP(18-22) complex were evaluated by electronic structure calculations and Born-Oppenheimer molecular dynamics. All models included a $3 \mathrm{~N} 1 \mathrm{O}$ equatorial coordination mode, where the three nitrogen ligands are provided by His 18 and backbone amides of Ser19 and 20, as described above. Different possibilities for the equatorial oxygen-based ligand were evaluated, including the $\mathrm{OH}$ group from Ser20 (named $3 \mathrm{NO}_{\mathrm{OH} / \mathrm{S} 20}$ ), the backbone carbonyl of Ser20 (named $3 \mathrm{NO}_{\mathrm{CO} / \mathrm{S} 20}$ ), the backbone carbonyl of Asn22 (named $3 \mathrm{NO}_{\mathrm{CO} / \mathrm{N} 22}$ ), or a water molecule. Furthermore, coordination of $\mathrm{Cu}$ (II) by the amino acid chain of Asn22 was also included for some models, where the $\mathrm{CONH}_{2}$ moiety acts as an axial ligand, namely, $3 \mathrm{NO}_{\mathrm{OH} / \mathrm{S} 20} \mathrm{O}_{\text {axialCO} / \mathrm{N} 22}$ and $3 \mathrm{NO}_{\mathrm{CO} / \mathrm{S} 20} \mathrm{O}_{\text {axialCO/N22. Solvation }}$ effects were included by geometry optimization of the models after adding four explicit water molecules. Figure 7 shows all geometry-optimized models; their structural and calculated EPR parameters are listed in Table S2, while selected parameters are listed in Table 3. It should be noted that a model with an equatorial water molecule could not be obtained, as the water ligand did not remain as part of the coordination shell upon geometry optimization. On the other hand, the model that includes the carbonyl group of Asn22 as an equatorial ligand has a relative energy of $38.7 \mathrm{kcal} / \mathrm{mol}$, strongly suggesting that Asn22 would not participate as an equatorial ligand for $\mathrm{Cu}(\mathrm{II})$ in this complex.

The two most stable models correspond to those with no axial ligand, where the equatorial oxygen-based ligand is provided by either the $\mathrm{OH}$ group of Ser20 $\left(3 \mathrm{NO}_{\mathrm{OH} / \mathrm{S} 20}\right)$ or by the backbone carbonyl of Ser20 $\left(3 \mathrm{NO}_{\mathrm{CO} / \mathrm{S} 20}\right)$, with relative energies of 0.0 and $3.4 \mathrm{kcal} / \mathrm{mol}$, respectively. This energetic

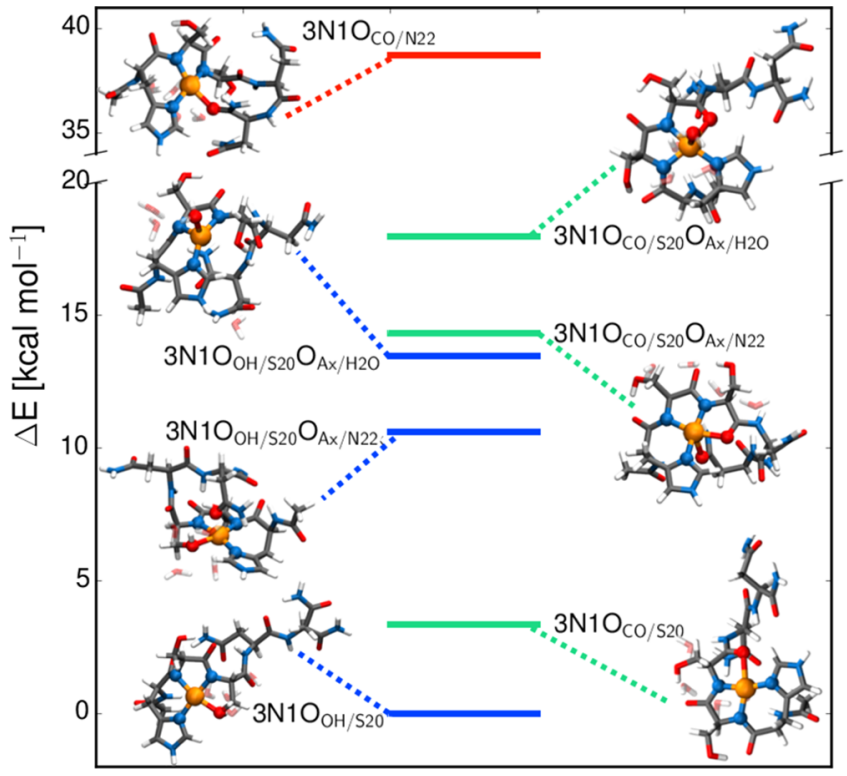

Figure 7. Optimized structural models for $\mathrm{Cu}(\mathrm{II})$ bound to the hIAPP(18-22) fragment.

difference is very small, and in fact, a BOMD simulation with these two structures shows that their relative stabilities are very similar (Figure S3), and thus, both are plausible models for the equatorial coordination shell. Still, it should be noted that all models where the equatorial ligand is provided by the $\mathrm{OH}$ group of Ser 20 are $3-5 \mathrm{kcal} / \mathrm{mol}$ more stable than the corresponding structures with the backbone carbonyl of Ser20 (Table 3). This observation is consistent with the experimental 
Table 3. Relative Energies, Calculated EPR Parameters, and Bond Distances ${ }^{a}$ for Selected Models

\begin{tabular}{|c|c|c|c|c|c|c|c|c|}
\hline model & $\exp$ & $3 \mathrm{NO}_{\mathrm{OH} / \mathrm{S} 20}$ & $3 \mathrm{NO}_{\mathrm{OH} / \mathrm{s} 20} \mathrm{O}_{\mathrm{Ax} / \mathrm{N} 22}$ & $3 \mathrm{NO}_{\mathrm{OH} / \mathrm{S} 20} \mathrm{O}_{\mathrm{Ax} / \mathrm{H}_{2} \mathrm{O}}$ & $3 \mathrm{~N} 1 O_{\mathrm{CO} / \mathrm{s} 20}$ & $3 \mathrm{NO}_{\mathrm{CO} / \mathrm{S} 20} \mathrm{O}_{\mathrm{Ax} / \mathrm{N} 22}$ & $3 \mathrm{NO}_{\mathrm{CO} / \mathrm{S} 20} \mathrm{O}_{\mathrm{Ax} / \mathrm{H}_{2} \mathrm{O}}$ & $3 \mathrm{~N} 1 O_{\mathrm{CO} / \mathrm{N} 22}$ \\
\hline$E_{\text {rel }}[\mathrm{kcal} / \mathrm{mol}]$ & N.A. & 0.00 & 10.63 & 13.47 & 3.36 & 14.32 & 18.00 & 38.73 \\
\hline$g_{x}$ & 2.055 & 2.042 & 2.045 & 2.029 & 2.047 & 2.055 & 2.035 & 2.054 \\
\hline$g_{y}$ & 2.087 & 2.057 & 2.071 & 2.146 & 2.066 & 2.081 & 2.098 & 2.057 \\
\hline$g_{z}$ & 2.239 & 2.157 & 2.174 & 2.217 & 2.176 & 2.194 & 2.188 & 2.185 \\
\hline$A_{z}(\mathrm{MHz})$ & 474 & -486 & -424 & 417 & -437 & -477 & -407 & -519 \\
\hline $\mathrm{Cu}-\mathrm{N}_{\mathrm{H} 18}$ & N.D. & 1.97 & 1.95 & 1.96 & 1.95 & 2.01 & 1.98 & 2.01 \\
\hline $\mathrm{Cu}-\mathrm{N}_{\mathrm{S} 19}^{-}$ & N.D. & 2.05 & 2.03 & 2.16 & 1.99 & 2.04 & 2.03 & 2.00 \\
\hline $\mathrm{Cu}-\mathrm{N}_{\mathrm{S} 20}^{-}$ & N.D. & 1.90 & 1.91 & 1.92 & 1.91 & 1.93 & 1.95 & 2.01 \\
\hline $\mathrm{Cu}-\mathrm{O}_{\mathrm{S} 20}{ }^{b}$ & N.D. & 2.12 & 2.26 & 2.57 & 2.40 & 2.20 & 2.26 & 2.17 \\
\hline $\mathrm{Cu}-\mathrm{O}_{\text {Axial }}{ }^{c}$ & N.D. & & 2.74 & 2.22 & & 2.35 & 2.35 & 3.11 \\
\hline
\end{tabular}

${ }^{a}$ Bond distances are given in $\AA .{ }^{b} \mathrm{Cu}-\mathrm{O}_{\mathrm{S} 20}$ refers to equatorial $\mathrm{Cu}-\mathrm{O}$ bond, which could be backbone $\mathrm{CO}$ or $\mathrm{OH}$ moiety from Ser20, depending on the model. ${ }^{c} \mathrm{Cu}-\mathrm{O}_{\text {Axial }}$ refers to axial $\mathrm{Cu}-\mathrm{O}$ bond, which could be the amide $\mathrm{CO}$ moiety from Asn22 or an axial water, depending on the model.

Scheme 1. Two Proposed 3N1O Equatorial Coordination Modes for the Cu(II)-hIAPP Complex where the Oxygen-Based Ligand Is Provided by Either the Hydroxyl Group of Ser20 $\left(3 \mathrm{~N} 1 \mathrm{O}_{\mathrm{OH} / \mathrm{S} 20}\right)$ or the Backbone Carbonyl of the Same Residue $\left(3 \mathrm{~N} 1 \mathrm{O}_{\mathrm{CO} / \mathrm{S} 20}\right)^{a}$

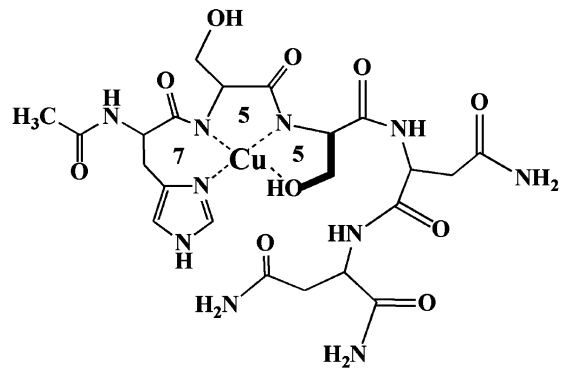

$3 \mathrm{~N}^{10} \mathrm{O}_{\mathrm{OH} / \mathrm{S20}}$

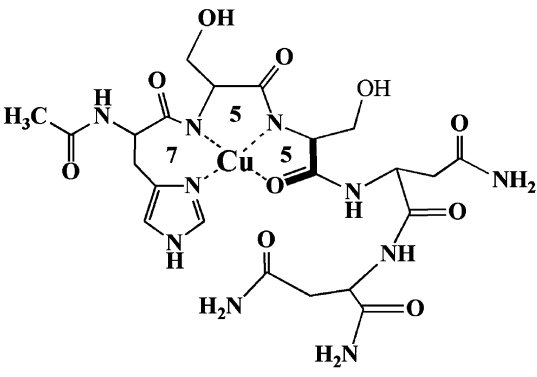

$3 \mathrm{~N}_{10} \mathrm{C}_{\mathrm{CO} / \mathrm{S} 20}$

${ }^{a}$ In both cases, Asn22 may act as an axial ligand $\left(3 \mathrm{NO}_{\mathrm{S} 20} \mathrm{O}_{\mathrm{Ax} / \mathrm{N} 22}\right)$. These species may coexist, although the $3 \mathrm{~N}_{1} \mathrm{O}_{\mathrm{OH} / \mathrm{S} 20}$ structure is favored.

results that reveal an important role of the $\mathrm{OH}$ group of Ser20 in $\mathrm{Cu}(\mathrm{II})$ coordination to $\mathrm{hIAPP}(18-22)$. The calculated EPR parameters for these two complexes provide a reasonable description of the $g_{z}$ and $A_{z}$ values (Table 3), particularly for the hyperfine couplings, for which a difference between calculated and experimental values of $\sim 5 \%$ is considered acceptable for this type of calculation. ${ }^{58}$ Interestingly, the $3 \mathrm{NO}_{\mathrm{CO} / \mathrm{S} 20}$ model provides a better description of the $g_{z}$ value, while the $3 \mathrm{NO}_{\mathrm{OH} / \mathrm{S} 20}$ model has a better match for the experimental $A_{z}$. These calculated EPR parameters are also consistent with the experimental results for the S20A variant. If we assume that both $3 \mathrm{NO}_{\mathrm{OH} / \mathrm{S} 20}$ and $3 \mathrm{NO}_{\mathrm{CO} / \mathrm{S} 20}$ are plausible models for the $\mathrm{Cu}(\mathrm{II})-\mathrm{hIAPP}$ complex and may represent coexisting species; thus, the S20A variant would favor the $3 \mathrm{NO}_{\mathrm{CO} / \mathrm{S} 20}$ species, which is predicted to have a higher $g_{z}$ and a lower $A_{z}$ value. This is precisely the trend observed experimentally for the S20A variant. Thus, it is plausible that these two coordination modes, $3 \mathrm{NO}_{\mathrm{OH} / \mathrm{S} 20}$ and $3 \mathrm{NO}_{\mathrm{CO} / \mathrm{S} 20}$, could coexist; however, the drastic changes observed by $\mathrm{CD}$ for the S20A variant strongly suggest that the most populated coordination mode is $3 \mathrm{NO}_{\mathrm{OH} / \mathrm{S} 20}$.

Axial ligation by water molecules or by the $\mathrm{CONH}_{2}$ moiety of Asn22 was also evaluated, using the two most stable equatorial coordination shells, $3 \mathrm{NO}_{\mathrm{OH} / \mathrm{S} 20}$ and $3 \mathrm{NO}_{\mathrm{CO} / \mathrm{S} 20}$. The resulting structures with axial ligands are considerably higher in energy (about $10 \mathrm{kcal} / \mathrm{mol}$ for Asn22 and 13-15 kcal/mol for water) than the corresponding tetra-coordinated models with no axial ligation (Figure 7 and Table 3). The presence of a water molecule as an axial ligand improves significantly the description of the $g_{z}$ value, but it lowers $A_{z}$ to values that fall outside the acceptable range for this parameter; moreover, it yields more distorted structures with very rhombic $g_{x}$ and $g_{y}$ values, as demonstrated by the $3 \mathrm{NO}_{\mathrm{OH} / \mathrm{S} 20} \mathrm{O}_{\mathrm{AxH}_{2} \mathrm{O}}$ and $3 \mathrm{NO}_{\mathrm{CO} / \mathrm{S} 20} \mathrm{O}_{\mathrm{AxH}_{2} \mathrm{O}}$ models in Table 3. EPR simulations of the experimental spectrum of the $\mathrm{Cu}(\mathrm{II})$-hIAPP complex do not reflect such large rhombicity (Figure 1D, Tables 3 and S1). Thus, we conclude that axial ligation by a water molecule does not provide a good description of the $\mathrm{Cu}(\mathrm{II})$-hIAPP complex. On the other hand, axial ligation by the $\mathrm{CONH}_{2}$ moiety of Asn22 improves significantly the description of the $g_{z}$ value, while keeping a good description of the $\mathrm{Cu}$ hyperfine coupling, as shown for the $3 \mathrm{NO}_{\mathrm{OH} / \mathrm{S} 20} \mathrm{O}_{\mathrm{Ax} / \mathrm{N} 22}$ and $3 \mathrm{NO}_{\mathrm{CO} / \mathrm{S} 20} \mathrm{O}_{\mathrm{Ax} / \mathrm{N} 22}$ models in Table 3. Particularly, the calculated EPR parameters for the $3 \mathrm{NO}_{\mathrm{CO} / \mathrm{S} 20} \mathrm{O}_{\mathrm{Ax} / \mathrm{N} 22}$ structure are in excellent agreement with the experimental values. Thus, although the relative energy for this model is $11 \mathrm{kcal} / \mathrm{mol}$ higher than the corresponding model with no axial ligation, the possibility that Asn 22 may play a role as an axial ligand cannot be discarded.

Overall, our electronic structure studies validate that the equatorial coordination shell in the $\mathrm{Cu}$ (II)-hIAPP complex involve the imidazole nitrogen $\mathrm{N} 1$ of His18, the deprotonated amides of Ser19 and Ser20, and an oxygen-based ligand that can be provided either by the $\mathrm{OH}$ group of Ser20 or its backbone carbonyl, possibly leading to two coexisting species (Scheme 1). Our calculations also help discard the participation of water molecules in the coordination shell and the possibility of Asn 22 acting as an equatorial ligand, while the involvement of Asn22 as an axial ligand is plausible. 


\section{- DISCUSSION AND CONCLUSIONS}

Copper Coordination to hIAPP. Our spectroscopic and theoretical studies have elucidated the coordination features of $\mathrm{Cu}$ (II) bound to hIAPP, confirming the involvement of His 18 and the following residues toward the $\mathrm{C}$-terminal region, and defining the residues HSSNN of hIAPP $(18-22)$ as the minimal unit to model $\mathrm{Cu}$ binding to this peptide. $\mathrm{Cu}$ (II) coordinates to the $\mathrm{N} 1$ (oftentimes referred to as $\mathrm{N} \delta$ ) of His18, two deprotonated amides from Ser19 and Ser20 and one oxygenbased ligand provided by either the hydroxyl group or the backbone carbonyl of Ser20. For both of these two $3 \mathrm{~N} 1 \mathrm{O}$ coordination modes, a set of three chelate rings with seven, five, and five members is formed (Scheme 1); thus the impact of the chelate effect on the relative stability of these two species would be similar. Although we cannot discard the formation of the $3 \mathrm{~N} 1 \mathrm{O}$ coordination mode with the backbone carbonyl of Ser20, theoretical and spectroscopic results demonstrate that the binding mode with the hydroxyl group of Ser20 is favored, possibly due to the formation of a stronger $\mathrm{Cu}(\mathrm{II})-\mathrm{OH}$ bond ( $\mathrm{Cu}-\mathrm{O}$ bond distance is $2.12 \AA$ ), as compared to a weaker and more distorted $\mathrm{Cu}(\mathrm{II})-\mathrm{O}$ backbone carbonyl bond (with distance at $2.40 \AA$ ) (Table 3 and S2). In either case, it is clear that Ser20 plays a very important role in the overall stability of the complex, as it provides the backbone amide and the oxygenbased ligand needed to form the two five-membered rings in the $3 \mathrm{~N} 1 \mathrm{O}$ coordination mode.

Initial $\mathrm{Cu}(\mathrm{II})$ binding toward the $\mathrm{C}$-terminal region in Hiscontaining peptides is less common, as compared to binding toward the N-terminal, because the latter forms a more stable six-membered ring with the imidazole group and the His backbone amide, while binding toward the C-terminal amide yields a seven-membered ring. ${ }^{59}$ This has been the rationale used in a recent study by Magri et al, who erroneously concluded that copper coordination to hIAPP involves residues toward N-terminal domain. ${ }^{60}$ However, several factors dictate this binding preference, including the nature of the side chains in the vicinity of the His residue, the relative stability of the ring patterns that are formed in the chelate, and the number of deprotonated amides involved in metal binding. ${ }^{61}$ Moreover, in a $3 \mathrm{~N} 1 \mathrm{O}$ complex with two deprotonated amides, $\mathrm{Cu}$ (II) binding toward the $\mathrm{N}$-terminal amides yields a chelate with six-, five-, and seven-membered rings, which would be overall less stable than the resulting chelate from coordination toward the C-terminal amides, yielding a seven-, five-, and five-membered rings. ${ }^{61}$ One example of copper coordination toward the $\mathrm{C}$ terminal region is the octarepeat region of the human prion protein, where the Pro residue in the metal ion binding motif -PHGGGWSQ - prevents coordination toward the N-terminal region. ${ }^{62}$ Remarkably, the spectroscopic features of this binding site, particularly the $C D$ signals, are very similar to those observed in the hIAPP fragment studied here. In the case of hIAPP, the presence of bulky hydrophobic residues preceding His18 is likely the cause for $\mathrm{Cu}$ (II) coordination to occur toward the C-terminal region. Conversely, the insertion of a Pro in position 19 in our model peptide turned into a "breakpoint" in the metal ion coordination site, ${ }^{63,64}$ forcing $\mathrm{Cu}$ (II) coordination toward the N-terminal region, in a similar fashion as observed recently by Rowinska-Zyrek in the membrane disrupting fragment of $\operatorname{hIAPP}(1-19){ }^{65}$ This fragment lacks Ser20, which is a key residue to stabilize $\mathrm{Cu}(\mathrm{II})$ coordination toward the C-terminal region; consistently, the spectroscopic features reported for the $\mathrm{Cu}(\mathrm{II})$ complex with the $\mathrm{hIAPP}(1-$
19) fragment are remarkably similar to those observed here for the S19P variant. Overall, these observations and the fact that Ser to Sar substitutions have a significant impact on the spectroscopic features of the $\mathrm{Cu}$ (II)-hIAPP complex allow us to unequivocally conclude that $\mathrm{Cu}$ (II) coordination occurs toward the C-terminal, involving the deprotonated backbone amides of Ser19 and Ser20.

Copper Coordination Involves Key Residues for Aggregation. The coordination sphere around the metal ion in the $\mathrm{Cu}(\mathrm{II})$-hIAPP complex involves key residues that play a very important role in hIAPP aggregation. His18 is the anchoring residue for $\mathrm{Cu}(\mathrm{II})$ coordination to the disordered peptide, ${ }^{29}$ and at the same time, it is located right in the middle of the $\beta$-sheet structure in the hIAPP fibrils. ${ }^{66,67}$ Thus, $\mathrm{Cu}(\mathrm{II})$ binding to hIAPP inevitably competes with $\beta$-sheet formation, ${ }^{17}$ and it has an inhibitory effect in amyloid aggregation. ${ }^{29}$ In this study we have also identified Ser20 as a key residue that stabilizes $\mathrm{Cu}(\mathrm{II})$ coordination to hIAPP, by providing the ligands needed to form a stable chelate with two five-membered rings. Interestingly, S20G is a natural mutation of hIAPP associated with early onset of type 2 diabetes in certain Asian populations, and it accelerates hIAPP amyloid aggregation in vitro. $^{9,68,69}$ The impact of the S20G mutation in the folding of the peptide and the mechanism involved in its accelerated amyloid aggregation are unknown, although the less bulky Gly residue at position 20 might facilitate the formation of the $\beta$ sheet structure, as this residue is located at the loop turn in the fibril structure. ${ }^{67}$ However, from what we now know about $\mathrm{Cu}$ (II) coordination to hIAPP, one would expect that the S20G natural mutation would impact significantly the ability of the peptide to coordinate $\mathrm{Cu}$ (II) ions, which in turn would affect its conformation and its ability to form amyloid fibrils. Given the inhibitory effect of $\mathrm{Cu}$ (II) coordination in hIAPP fibril formation, decreased $\mathrm{Cu}$ (II) binding to the S20G variant would result in increased amyloid aggregation, potentially explaining the early onset of type 2 diabetes in those patients.

It has been demonstrated that the amide side chains of the asparagine residues 21 and 22 can dictate specific interactions that contribute to the ability of hIAPP to form fibers. ${ }^{70}$ Here, we found that these asparagines residues may also play a role in $\mathrm{Cu}$ (II) binding, particularly Asn22 as a potential axial ligand to copper. Although the relative energy of the coordination models that include this residue as an axial ligand are 10-14 $\mathrm{kcal} / \mathrm{mol}$ higher than the most stable structure, the spectroscopic changes observed upon substitutions of Asn22 indicate a role for the amide side chain of this residue in $\mathrm{Cu}$ (II) coordination. Interestingly, the coordination mode that includes the backbone carbonyl of Ser20 as an equatorial ligand and the $-\mathrm{CO}-\mathrm{NH}_{2}$ moiety of Asn22 as an axial ligand (i.e., $3 \mathrm{NO}_{\mathrm{CO} / \mathrm{S} 20} \mathrm{O}_{\mathrm{Ax} / \mathrm{N} 22}$ ) is the structure that best reproduces the experimental EPR parameters. Thus, it is tempting to propose that this coordination mode might coexist with the modes shown in Scheme 1, even if it might be less populated. If so, the participation of Asn22 in $\mathrm{Cu}$ (II) coordination would further contribute to the inhibitory effect of this metal ion in hIAPP amyloid aggregation. Moreover, for Asn22 to reach into the metal ion coordination shell, a larger conformational change in the peptide would be needed, thus favoring a potentially different set of peptide conformations.

Copper Binding May Impact hIAPP Conformation. Human IAPP is an intrinsically disordered peptide with a flexible random coil fold that would be capable of adopting different conformations upon interaction with other molecules. 


\section{Scheme 2. Conformational Energy Landscapes for Metal-Free and $\mathrm{Cu}$ (II)-Bound hIAPP ${ }^{a}$}

A

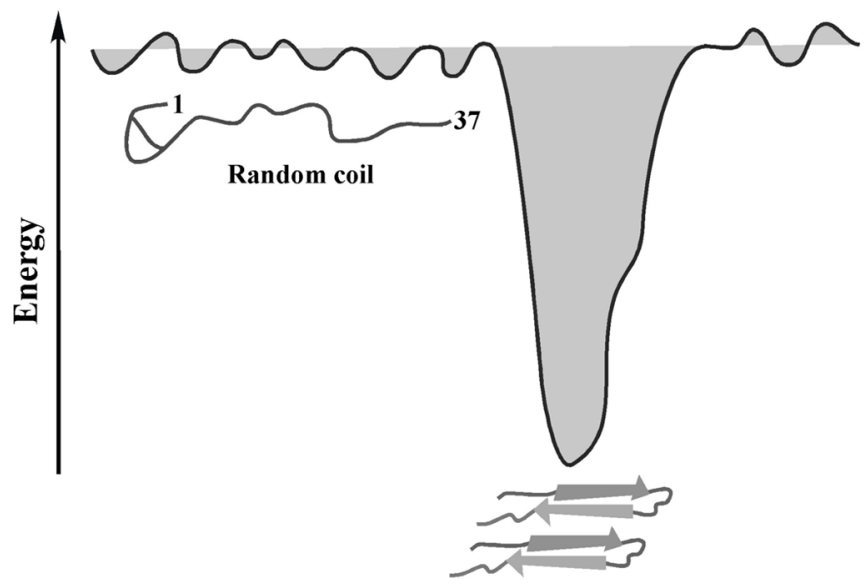

Amyloid fibrils
B Cu(II)-bound hIAPP

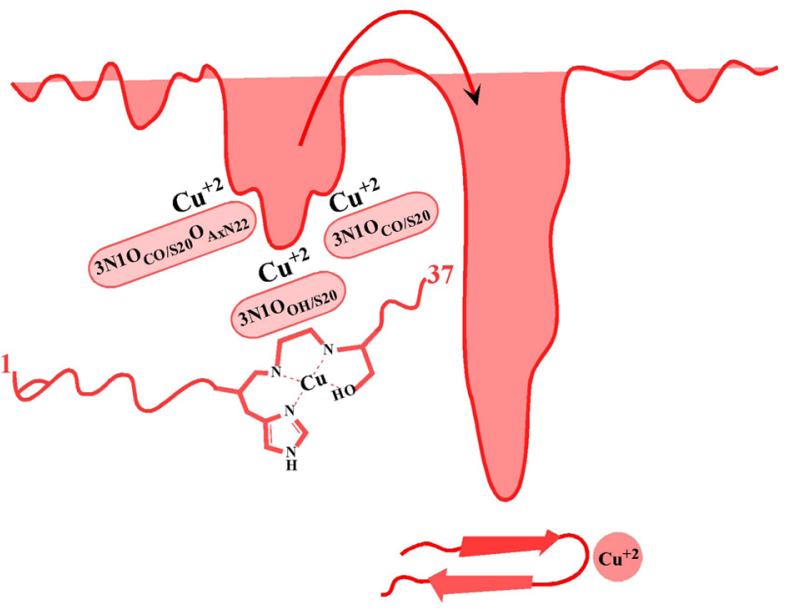

Amyloid fibrils

${ }^{a}$ Intrinsically disordered peptides such as hIAPP have flexible random coil conformations and thus, have a "flatter" conformational energy landscape (A). hIAPP conversion to beta-sheet structures facilitate the irreversible formation of highly stable amyloid fibrils (energy well in A). Metal ion binding to hIAPP would impact this conformational energy landscape, stabilizing a set of conformers that would encounter a higher energy barrier (red arrow) for their conversion to -sheet structures and amyloid aggregation (B).

In the secretory granules, hIAPP is exposed to insulin and hormone peptides, as well as metal ions such as zinc and copper. ${ }^{11}$ Because of this, it is reasonable to propose that the interaction of hIAPP with some of these physiologically relevant molecules might impact its conformation and hence modulate its aggregation properties. For instance, it has been proposed that the interaction of insulin with hIAPP inhibits its amyloid aggregation, ${ }^{11}$ perhaps favoring a particular set of hIAPP conformers. In this context, the notion that $\mathrm{Cu}(\mathrm{II})$ binding to hIAPP might lead to different coexisting coordination modes that in turn could favor different sets of $\mathrm{Cu}$-induced conformational ensembles is appealing (Scheme 2 ). Similar to the case of the amyloid- $\beta$ peptide associated with Alzheimer's disease, ${ }^{71}$ our study points to a scenario where $\mathrm{Cu}$ (II) binding to hIAPP might lead to the coexistence of more than one coordination mode, namely, $3 \mathrm{NO}_{\mathrm{OH} / \mathrm{S} 20}$ and $3 \mathrm{NO}_{\mathrm{CO} / \mathrm{S} 20}$, and possibly a coordination mode where Asn22 would act as an axial ligand $\left(3 \mathrm{NO}_{\mathrm{CO} / \mathrm{S} 20} \mathrm{O}_{\mathrm{Ax} / \mathrm{N} 22}\right)$. Since each of these species would impose different strains in the backbone peptide conformation, this dynamic coordination scenario would lead to the stabilization of different sets of hIAPP conformers that would be distinct from those associated with metal-free hIAPP (Scheme 2). Indeed, a recent mass spectrometry and molecular dynamics study has determined that $\mathrm{Cu}$ (II) binding to hIAPP favors the formation of conformers and oligomeric species that differ from those observed in metal-free hIAPP samples. ${ }^{17}$

Metal-induced changes in the folding of hIAPP would impact different properties of this peptide. For instance, many studies have demonstrated that $\mathrm{Cu}$ (II) binding to hIAPP protects it from enzymatic degradation by the insulin-degrading enzyme (IDE), particularly in the region around His18. ${ }^{30,31}$ In a similar fashion as $\mathrm{Cu}(\mathrm{II})$ ions, $\mathrm{Zn}$ (II) and $\mathrm{Ni}(\mathrm{II})$ binding to His 18 of hIAPP inhibits its amyloid aggregation by changing its local conformation nearby this residue. ${ }^{11,16,19}$ In this regard, the effect of His-binding metal ions in hIAPP differs from the scenario observed for the amyloid- $\beta$ peptide. The His residues that anchor $\mathrm{Cu}$ (II) and $\mathrm{Zn}$ (II) ions to the amyloid- $\beta$ peptide are located in the hydrophilic $\mathrm{N}$-terminal region and do not compete with the formation of $\beta$-sheet structures and fibrils. ${ }^{72}$ In contrast, the anchoring His residue for metal ions in hIAPP is located in the middle of the hydrophobic region of the peptide that participates in $\beta$-sheet formation. ${ }^{67}$ Thus, $\mathrm{Cu}$ (II) binding to hIAPP would favor a set of peptide conformers that would not be amenable for conversion into $\beta$-sheet structures, raising the energetic barrier toward amyloid fibril formation (Scheme 2). Cu-induced hIAPP conformers would not only be less likely to form amyloid structures, but could actually promote the formation of off-pathway aggregates that may be more toxic to cells. ${ }^{17}$

In summary, our study has revealed structural details of the $\mathrm{Cu}$ (II)-hIAPP complex, and it has identified the key residues involved in metal ion coordination. Beyond the anchoring His 18 residue, Ser19 and Ser20 also play important roles by providing the deprotonated backbone amides that yield a $3 \mathrm{~N}$ equatorial coordination mode. Most importantly, Ser20 plays the crucial role of stabilizing $\mathrm{Cu}$ (II) coordination toward the $\mathrm{C}$ terminal region of hIAPP, as it provides the oxygen-based equatorial ligand, either via its hydroxyl group or its backbone carbonyl, that yields two $3 \mathrm{~N} 1 \mathrm{O}$ coordination modes with a stable set of chelate rings. Our finding that Ser20 plays an important role in $\mathrm{Cu}(\mathrm{II})$ coordination to hIAPP provides a potential link between the S20G mutation associated with early onset of type 2 diabetes, its impact in $\mathrm{Cu}$ binding properties, and hIAPP amyloid aggregation. On the other hand, our study points to a scenario where $\mathrm{Cu}$ (II) binding to hIAPP might lead to the coexistence of more than one coordination mode, which in turn could favor different sets of $\mathrm{Cu}$-induced conformational ensembles. Because metal ion coordination involves residues that are key for the formation of $\beta$-sheet structures, such $\mathrm{Cu}$ induced hIAPP conformers would display a higher energetic barrier to form amyloid fibrils, hence explaining the inhibitory 
effect of $\mathrm{Cu}$ ions in hIAPP aggregation. Overall, this study provides further structural insights into the bioinorganic chemistry of type 2 diabetes.

\section{ASSOCIATED CONTENT}

\section{S Supporting Information}

The Supporting Information is available free of charge on the ACS Publications website at DOI: 10.1021/acs.inorgchem.6b01963.

$\mathrm{pH}$ titration of $\mathrm{hIAPP}(18-22)-\mathrm{Cu}(\mathrm{II})$ complex as followed by CD; 1D ${ }^{1} \mathrm{NMR}$ spectra of hIAPP $(18-22)$ in the absence and presence of $\mathrm{Cu}(\mathrm{II})$; total energies of the model systems along the BOMD trajectory; EPR parameters from simulation of the complexes and structural parameters for the models from theoretical studies. Cartesian coordinates for all models are available upon request (PDF)

\section{AUTHOR INFORMATION}

\section{Corresponding Author}

*Phone: +52-55-57473723. E-mail: lilianaq@cinvestav.mx.

\section{Notes}

The authors declare no competing financial interest.

\section{ACKNOWLEDGMENTS}

This research was funded by the National Council for Science and Technology in Mexico (CONACYT) through Grant No. 221134 to L.Q., and graduate fellowships to C.S.L. and R.C.M. J.M.C. acknowledges DGTIC-UNAM Project SC16-1-IR-12 for the use of their computational resources and DGAPA-UNAM Grant IA-104516. The authors would also like to thank Dr. Lina Rivillas-Acevedo for the initial characterization of $\mathrm{Cu}$ (II)hIAPP(15-22) complex, I. Q. Geiser Cuellar for assistance with the acquisition of ESI-MS data, and Q. Atenea Villegas and Q. F. I. Yanahi Posadas-Torrentera for assistance with peptide synthesis and purification.

\section{REFERENCES}

(1) Westermark, P.; Andersson, A.; Westermark, G. T. Islet amyloid polypeptide, islet amyloid, and diabetes mellitus. Physiol. Rev. 2011, 91, 795-826.

(2) Jaikaran, E. T. A. S.; Clark, A. Islet amyloid and type 2 diabetes from molecular misfolding to islet pathophysiology. Biochim. Biophys. Acta, Mol. Basis Dis. 2001, 1537, 179-203.

(3) Marzban, L.; Park, K.; Verchere, C. B. Islet amyloid polypeptide and type 2 diabetes. Exp. Gerontol. 2003, 38, 347-351.

(4) Kahn, C. R. Insulin Action, Diabetogenes, and the Cause of Type II Diabetes. Diabetes 1994, 43, 1066-1084.

(5) Rhodes, C. J. Type 2 Diabetes-a Matter of $\beta$-Cell Life and Death? Science 2005, 307, 380-384.

(6) Young, A. Amylin: Physiology and Pharmacology, 1st ed.; Elsevier Academic Press Inc.: Amsterdam, 2005; Vol. 52.

(7) Lorenzo, A.; Razzaboni, B.; Weir, G. C.; Yankner, B. A. Pancreatic islet cell toxicity of amylin associated with type-2 diabetes mellitus. Nature 1994, 368, 756-760.

(8) Cao, P.; Marek, P.; Noor, H.; Patsalo, V.; Tu, L.-H.; Wang, H.; Abedini, A.; Raleigh, D. P. Islet amyloid: from fundamental biophysics to mechanisms of cytotoxicity. FEBS Lett. 2013, 587, 1106-1118.

(9) Cao, P.; Tu, L.-H.; Abedini, A.; Levsh, O.; Akter, R.; Patsalo, V.; Schmidt, A. M.; Raleigh, D. P. Sensitivity of amyloid formation by human islet amyloid polypeptide to mutations at residue 20. J. Mol. Biol. 2012, 421, 282-295.

(10) Westermark, P.; Engström, U.; Johnson, K. H.; Westermark, G. T.; Betsholtz, C. Islet amyloid polypeptide: Pinpointing amino acid residues linked to amyloid fibril formation. Proc. Natl. Acad. Sci. U. S. A. 1990, 87, 5036-5040.

(11) DeToma, A. S.; Salamekh, S.; Ramamoorthy, A.; Lim, M. H. Misfolded proteins in Alzheimer's disease and type II diabetes. Chem. Soc. Rev. 2012, 41, 608-621.

(12) Binolfi, A.; Lamberto, G. R.; Duran, R.; Quintanar, L.; Bertoncini, C. W.; Souza, J. M.; Cerveñansky, C.; Zweckstetter, M.; Griesinger, C.; Fernández, C. O. Site-Specific Interactions of $\mathrm{Cu}(\mathrm{II})$ with $\alpha$ and $\beta$-Synuclein: Bridging the Molecular Gap between Metal Binding and Aggregation. J. Am. Chem. Soc. 2008, 130, 11801-11812.

(13) Hureau, C. Coordination of redox active metal ions to the amyloid precursor protein and to amyloid- $\beta$ peptides involved in Alzheimer disease. Part 1: An overview. Coord. Chem. Rev. 2012, 256, 2164-2174.

(14) Younan, N. D.; Klewpatinond, M.; Davies, P.; Ruban, A. V.; Brown, D. R; Viles, J. H. Copper(II)-induced secondary structure changes and reduced folding stability of the prion protein. J. Mol. Biol. 2011, 410, 369-82.

(15) Taylor, C. G. Zinc, the pancreas, and diabetes: insights from rodent studies and future directions. BioMetals 2005, 18, 305-312.

(16) Brender, J. R.; Hartman, K.; Nanga, R. P. R.; Popovych, N.; de la Salud Bea, R.; Vivekanandan, S.; Marsh, E. N. G.; Ramamoorthy, A. Role of Zinc in Human Islet Amyloid Polypeptide Aggregation. J. Am. Chem. Soc. 2010, 132, 8973-8983.

(17) Lee, S. J. C.; Choi, T. S.; Lee, J. W.; Lee, H. J.; Mun, D.-G.; Akashi, S.; Lee, S.-W.; Lim, M. H.; Kim, H. I. Structure and assembly mechanisms of toxic human islet amyloid polypeptide oligomers associated with copper. Chem. Sci. 2016, 7, 5398-5406.

(18) Brender, J. R.; Krishnamoorthy, J.; Messina, G. M. L.; Deb, A.; Vivekanandan, S.; La Rosa, C.; Penner-Hahn, J. E.; Ramamoorthy, A. Zinc stabilization of prefibrillar oligomers of human islet amyloid polypeptide. Chem. Commun. 2013, 49, 3339-3341.

(19) Salamekh, S.; Brender, J. R.; Hyung, S.-J.; Nanga, R. P. R.; Vivekanandan, S.; Ruotolo, B. T.; Ramamoorthy, A. A Two-Site Mechanism for the Inhibition of IAPP Amyloidogenesis by Zinc. J. Mol. Biol. 2011, 410, 294-306.

(20) Aspinwall, C. A.; Brooks, S. A.; Kennedy, R. T.; Lakey, J. R. T. Effects of Intravesicular $\mathrm{H}+$ and Extracelullar $\mathrm{H}+$ and $\mathrm{Zn2}+$ on Insulin Secretation in Pancreatic Beta Cells. J. Biol. Chem. 1997, 272, 3130831314 .

(21) Zargar, A. H.; Shah, N. A.; Masoodi, S. R.; Laway, B. A.; Dar, F. A.; Khan, A. R.; Sofi, F. A.; Wani, A. I. Copper, zinc, and magnesium levels in non-insulin dependent diabetes mellitus. Postgrad. Med. J. 1998, 74, 665-668.

(22) Kazi, T. G.; Afridi, H. I.; Kazi, N.; Jamali, M. K.; Arain, M. B.; Jalbani, N.; Kandhro, G. A. Copper, chromium, manganese, iron, nickel, and zinc levels in biological samples of diabetes mellitus patients. Biol. Trace Elem. Res. 2008, 122, 1-18.

(23) Tanaka, A.; Kaneto, H.; Miyatsuka, T.; Yamamoto, K.; Yoshiuchi, K.; Yamasaki, Y.; Shimomura, I.; Matsuoka, T.-A.; Matsuhisa, M. Role of Copper Ion in the Pathogenesis of Type 2 Diabetes. Endocr. J. 2009, 56, 699-706.

(24) Flores, C. R.; Puga, M. P.; Wrobel, K.; Garay Sevilla, M. E.; Wrobel, $\mathrm{K}$. Trace elements status in diabetes mellitus type 2: Possible role of the interaction between molybdenum and copper in the progress of typical complications. Diabetes Res. Clin. Pract. 2011, 91, 333-341.

(25) Naka, T.; Kaneto, H.; Katakami, N.; Matsuoka, T.-a.; Harada, A.; Yamasaki, Y.; Matsuhisa, M.; Shimomura, I. Association of serum copper levels and glycemic control in patients with type 2 diabetes. Endocr. J. 2013, 60, 393-396.

(26) Uriu-Adams, J. Y.; Keen, C. L. Copper, oxidative stress, and human health. Mol. Aspects Med. 2005, 26, 268-298.

(27) Ward, B.; Walker, K.; Exley, C. Copper(II) inhibits the formation of amylin amyloid in vitro. J. Inorg. Biochem. 2008, 102, $371-375$.

(28) Li, H.; Ha, E.; Donaldson, R. P.; Jeremic, A. M.; Vertes, A. Rapid Assessment of Human Amylin Aggregation and Its Inhibition by Copper(II) Ions by Laser Ablation Electrospray Ionization Mass 
Spectrometry with Ion Mobility Separation. Anal. Chem. 2015, 87, 9829-9837.

(29) Rivillas-Acevedo, L.; Sánchez-López, C.; Amero, C.; Quintanar, L. Structural Basis for the Inhibition of Truncated Islet Amyloid Polypeptide Aggregation by $\mathrm{Cu}(\mathrm{II})$ : Insights into the Bioinorganic Chemistry of Type II Diabetes. Inorg. Chem. 2015, 54, 3788-3796.

(30) Bellia, F.; Grasso, G. The role of copper(II) and zinc(II) in the degradation of human and murine IAPP by insulin-degrading enzyme. J. Mass Spectrom. 2014, 49, 274-279.

(31) Sinopoli, A.; Magri, A.; Milardi, D.; Pappalardo, M.; Pucci, P.; Flagiello, A.; Titman, J. J.; Nicoletti, V. G.; Caruso, G.; Pappalardo, G.; Grasso, G. The role of copper (II) in the agregation of human amylin. Metallomics 2014, 6, 1841-1852.

(32) Hu, J.; Yu, Y.-P.; Cui, W.; Fang, C.-L.; Wu, W.-H.; Zhao, Y.-F.; Li, Y.-M. Cyclen-hybrid compound captures copper to protect INS-1 cells from islet amyloid polypeptide cytotoxicity by inhibiting and lysing effects. Chem. Commun. 2010, 46, 8023-8025.

(33) Yu, Y.-P.; Lei, P.; Hu, J.; Wu, W.-H.; Zhao, Y.-F.; Li, Y.-M. Copper induced citotoxicity: reactive oxygen species or islet amyloid polypeptide oligomer formation. Chem. Commun. 2010, 46, 69096911.

(34) Ma, L.; Li, X.; Wang, Y.; Zheng, W.; Chen, T. Cu(II) inhibits hIAPP fibrillation and promotes hIAPP-induced beta cell apoptosis through induction of ROS-mediated mitochondrial dysfunction. $J$. Inorg. Biochem. 2014, 140, 143-152.

(35) Masad, A.; Hayes, L.; Tabner, B. J.; Turnbull, S.; Cooper, L. J.; Fullwood, N. J.; German, M. J.; Kametani, F.; El-Agnaf, O. M. A.; Allsop, D. Copper-mediated formation of hydrogen peroxide from the amylin peptide: A novel mechanism for degeneration of islet cells in type-2 diabetes mellitus? FEBS Lett. 2007, 581, 3489-3493.

(36) Jensen, K. J.; Shelton, P. T.; Pedersen, S. L. Peptide Synthesis and Applications, 2nd ed.; Humana Press: New York, 2013; p 253.

(37) Subirós-Funosas, R.; Prohens, R.; Barbas, R.; El-Faham, A.; Albericio, F. Oxyma: an efficient additive for peptide synthesis to replace the benzotriazole-based $\mathrm{HOBt}$ and HOAt with a lower risk of explosion. Chem. - Eur. J. 2009, 15, 9394-9403.

(38) Gaggelli, E.; Bernardi, F.; Molteni, E.; Pogni, R.; Valensin, D.; Valensin, G.; Remelli, M.; Luczkowski, M.; Kozlowski, H. Interaction Of The Human Prion $\operatorname{PrP}(106-126)$ Sequence With Copper(II), Manganese(II), And Zinc(II): NMR and EPR Studies. J. Am. Chem. Soc. 2005, 127, 996-1006.

(39) Huber, J. G.; Moulis, J.-M.; Gaillard, J. Use of $1 \mathrm{H}$ Longitudinal Relaxation Times in the Solution Structure of Paramagnetic Proteins. Application to [4Fe-4S] Proteins. Biochemistry 1996, 35, 1270512711.

(40) Bertini, I.; Luchinat, C. Coord. Chem. Rev. 1996, 150, 1-292.

(41) Solomon, I. Relaxation Processes in a System of Two Spins. Phys. Rev. 1955, 99, 559-565.

(42) Vranken, W. F.; Boucher, W.; Stevens, T. J.; Fogh, R. H.; Pajon, A.; Llinas, M.; Ulrich, E. L.; Markley, J. L.; Ionides, J.; Laue, E. D. The CCPN data model for NMR spectroscopy: development of a software pipeline. Proteins: Struct., Funct., Genet. 2005, 59, 687-696.

(43) Schaftenaar, G.; Noordik, J. H. Molden: a pre- and postprocessing program for molecular and electronic structures. J. Comput.Aided Mol. Des. 2000, 14, 123-134.

(44) Ufimtsev, I. S.; Martinez, T. J. Quantum Chemistry on Graphical Processing Units. 3. Analytical Energy Gradients, Geometry Optimization, and First Principles Molecular Dynamics. J. Chem. Theory Comput. 2009, 5, 2619-2628.

(45) Perdew, J. P.; Burke, K.; Ernzerhof, M. Generalized Gradient Approximation Made Simple. Phys. Rev. Lett. 1996, 77, 3865-3868.

(46) Godbout, N.; Salahub, D. R.; Andzelm, J.; Wimmer, E. Optimization of Gaussian-type basis sets for local spin density functional calculations. Part I. Boron through neon, optimization technique and validation. Can. J. Chem. 1992, 70, 560-571.

(47) Geudtner, G.; Calaminici, P.; Carmona-Espíndola, J.; del Campo, J. M.; Domínguez-Soria, V. D.; Moreno, R. F.; Gamboa, G. U.; Goursot, A.; Köster, A. M.; Reveles, J. U.; Mineva, T.; Vásquez-
Pérez, J. M.; Vela, A.; Zúñinga-Gutierrez, B.; Salahub, D. R. deMon2k. WIREs Comput. Mol. Sci. 2012, 2, 548-555.

(48) Neese, F. The ORCA program system. WIREs Comput. Mol. Sci. 2012, 2, 73-78.

(49) Ernzerhof, M.; Scuseria, G. E. Assessment of the PerdewBurke-Ernzerhof exchange-correlation functional. J. Chem. Phys. 1999, $110,5029$.

(50) Adamo, C.; Barone, V. Toward reliable density functional methods without adjustable parameters: The PBE0 model. J. Chem. Phys. 1999, 110, 6158-6170.

(51) The ORCA basis set CoreProp was used. This basis is based on the TurboMole DZ basis developed by Ahlrichs and co-workers and obtained from the basis set library under ftp.chemie.unikarlsruhe.de/ pub/basen

(52) Daniele, P. G.; Prenesti, E.; Ostacoli, G. Ultraviolet-circular dichroism spectra for structural analysis of copper (II) complexes with aliphatic and aromatic ligands in aqueous solution. J. Chem. Soc., Dalton Trans. 1996, 3269-3275.

(53) Bernarducci, E.; Schwindinger, W. F.; Hughey, J. L.; KroghJespersen, K.; Schugar, H. J. Electronic Spectra of Copper(II)Imidazole and Copper(II)-Pyrazole Chromophores. J. Am. Chem. Soc. 1981, 103, 1686-1691.

(54) Peisach, J.; Blumberg, W. E. Structural implications derived from the analysis of electron paramagnetic resonance spectra of natural and artificial copper proteins. Arch. Biochem. Biophys. 1974, 165, 691-708.

(55) Bertini, I.; Luchinat, C.; Parigi, G.; Pierattelli, R. NMR spectroscopy of paramagnetic metalloproteins. ChemBioChem 2005, 6, 1536-1549.

(56) Gaggelli, E.; Kozlowski, H.; Valensin, D.; Valensin, G. NMR studies on $\mathrm{Cu}(\mathrm{II})$-peptide complexes: exchange kinetics and determination of structures in solution. Mol. BioSyst. 2005, 1, 79-84. (57) Binolfi, A.; Rodríguez, E. E.; Valensin, D.; D'Amelio, N.; Ippoliti, E.; Obal, G.; Duran, R.; Magistrato, A.; Pritsch, O.; Zweckstetter, M.; Valensin, G.; Carloni, P.; Quintanar, L.; Griesinger, C.; Fernández, C. O. Bioinorganic chemistry of Parkinson's disease: structural determinants for the copper-mediated amyloid formation of alpha-synuclein. Inorg. Chem. 2010, 49, 10668-10679.

(58) Neese, F. Metal and ligand hyperfine couplings in transition metal complexes: The effect of spin-orbit coupling as studied by coupled perturbed Kohn-Sham theory. J. Chem. Phys. 2003, 118, 3939-3948.

(59) Barry, S. D.; Rickard, G. A.; Pushie, M. J.; Rauk, A. The affinity of HGGG, GHGG, GGHG, and GGGH peptides for copper(II) and the structures of their complexes - An ab initio study. Can. J. Chem. 2009, 87, 942-953.

(60) Magrì, A.; La Mendola, D.; Nicoletti, V. G.; Pappalardo, G.; Rizzarelli, E. New Insight in Copper-Ion Binding to Human Islet Amyloid: The Contribution of Metal-Complex Speciation To Reveal the Polypeptide Toxicity. Chem. - Eur. J. 2016, 22, 13287-13300.

(61) Grande-Aztatzi, R.; Rivillas-Acevedo, L.; Quintanar, L.; Vela, A. Structural models for $\mathrm{Cu}$ (II) bound to the fragment $92-96$ of the human prion protein. J. Phys. Chem. B 2013, 117, 789-799.

(62) Burns, C. S.; Aronoff-Spencer, E.; Dunham, C. M.; Lario, P.; Avdievich, N. I.; Antholine, W. E.; Olmstead, M. M.; Vrielink, A.; Gerfen, G. J.; Peisach, J.; Scott, W. G.; Millhauser, G. L. Molecular Features of the Copper Binding Sites in the Octarepeat Domain of the Prion Protein. Biochemistry 2002, 41, 3991-4001.

(63) Bataille, M.; Formicka-Kozlowska, G.; Kozlowski, H.; Pettit, L. D.; Steel, I. The L-proline residues as a break-point in the coordination of metal-peptide systems. J. Chem. Soc., Chem. Commun. 1984, 231232.

(64) Pettit, L. D.; Steel, I.; Formicka-Kozlowska, G.; Tatarowski, T.; Bataille, M. The L-Proline Residues as a Break-point in Metal-Peptide System. J. Chem. Soc., Dalton Trans. 1985, 535-539.

(65) Rowinska-Zyrek, M. Coordination of $\mathrm{Zn}(2+)$ and $\mathrm{Cu}(2+)$ to the membrane disrupting fragment of amylin. Dalton Trans. 2016, 45, 8099-8106.

(66) Luca, S.; Yau, W.-M.; Leapman, R.; Tycko, R. Peptide Conformation and Supramolecular Organization in Amylin Fibrils: 
Constraints from Solid-State NMR. Biochemistry 2007, 46, 1350513522.

(67) Wiltzius, J. J.; Sievers, S. A.; Sawaya, M. R.; Cascio, D.; Popov, D.; Riekel, C.; Eisenberg, D. Atomic structure of the cross-beta spine of islet amyloid polypeptide (amylin). Protein Sci. 2008, 17, 14671474.

(68) Sakagashira, S.; Hiddinga, H. J.; Tateishi, K.; Sanke, T.; Hanabusa, T.; Nanjo, K.; Eberhardt, N. L. S20G Mutant Amylin Exhibits Increased in Vitro Amyloidogenicity and Increased Intracellular Cytotoxicity Compared to Wild-Type Amylin. Am. J. Pathol. 2000, 157, 2101-2109.

(69) Xu, W.; Jiang, P.; Mu, Y. Conformation Preorganization: Effects of S20G Mutation on the Structure of Human Islet Amyloid Polypeptide Segment. J. Phys. Chem. B 2009, 113, 7308-7314.

(70) Koo, B. W.; Hebda, J. A.; Miranker, A. D. Amide inequivalence in the fibrillar assembly of islet amyloid polypeptide. Protein Eng., Des. Sel. 2008, 21, 147-154.

(71) Faller, P.; Hureau, C.; La Penna, G. Metal ions and intrinsically disordered proteins and peptides: from $\mathrm{Cu} / \mathrm{Zn}$ amyloid-beta to general principles. Acc. Chem. Res. 2014, 47, 2252-9.

(72) Nasica-Labouze, J.; Nguyen, P. H.; Sterpone, F.; Berthoumieu, O.; Buchete, N. V.; Cote, S.; De Simone, A.; Doig, A. J.; Faller, P.; Garcia, A.; Laio, A.; Li, M. S.; Melchionna, S.; Mousseau, N.; Mu, Y.; Paravastu, A.; Pasquali, S.; Rosenman, D. J.; Strodel, B.; Tarus, B.; Viles, J. H.; Zhang, T.; Wang, C.; Derreumaux, P. Amyloid beta Protein and Alzheimer's Disease: When Computer Simulations Complement Experimental Studies. Chem. Rev. 2015, 115, 3518-63. 